\title{
2. EL CONSEJO GENERAL DEL PODER JUDICIAL: DE LA LEY ORGÁNICA 1/1980, DE 10 DE ENERO, A LA LEY ORGÁNICA 6/1985, DE 29 DE JULIO
}

CARMEN FERNÁNDEZ-MIRANDA CAMPOAMOR

Profesora Titular de Derecho Constitucional 


\title{
SUMARIO
}

\begin{abstract}
A) Introducción.-B) La justificación histórica del Consejo General del Poder Judicial. - C) El Consejo General del Poder Judicial en la CONSTITUCIÓN DE 1978.-1. Características generales.-2. Competencias.-3. Responsabilidad del órgano.-4. Estatuto jurídico de sus miembros.-D) ELECCIÓN DE LOS VoCAleS DEL CONSEJO.- 1. Criterios expuestos por los grupos parlamentarios en la discusión del Proyecto de Ley.-2. Causas de la modificación introducida en la Ley Orgánica del Poder Judicial.-3. Desarro110 de las elecciones del segundo y tercer Consejo; repercusiones en la opinión pública.-E) ANÁLISIS DE LOS CRITERIOS MANIFESTAdOS POR LOS DISTINTOS CONSEJOS EN LAS MEMORIAS. - 1. El primer Consejo General del Poder Judicial (1980-85).-2. El segundo Consejo General del Poder Judicial (1985-90). - 3. El tercer Consejo General del Poder Judicial (1990-95).-F) CoNCLUSIÓN.
\end{abstract}


Revista de Derecho Político, núm. 38, 1994, pp. 37-92

\section{EL CONSEJO GENERAL DEL PODER JUDICIAL: DE LA LEY ORGÁNICA 1/1980, DE 10 DE ENERO, A LA LEY ORGÁNICA 6/1985, DE 29 DE JULIO (*)}

POR

CARMEN FERNÁNDEZ-MIRANDA CAMPOAMOR

Profesora Titular de Derecho Constitucional

\section{A) INTRODUCCIÓN}

Las Constituyentes de 1978 denominaron solemnemente "Del Poder Judicial" al Título VI de la Constitución ${ }^{1}$, en una pretensión de subrayar la importancia de la potestad jurisdiccional en el Estado democrático actual, importancia que no se consideró necesario resaltar respecto a los poderes Legislativo y Ejecutivo. El creciente valor de la función jurisdiccional es indiscutible: a ella están sometidos tanto los particulares como el poder público; en consecuencia, la independencia de los jueces en el ejercicio de sus funciones, que les permita recrear el derecho de modo imparcial, es, en palabras de Loewenstein, "la piedra final en el edifició del Estado democrático constitucional de Derecho" ${ }^{2}$.

(*) Este trabajo fue entregado para su publicación en marzo de 1992.

1 Denominación que coincide con la utilizada en las Constituciones de 1837, 1856, 1869 y 1873 (en ésta se dice expresamente que el Poder Judicial no emana ni del Poder Ejecutivo ni del Legislativol, mientras que las Constituciones de 1845 y 1876 se refieren a la Administración de Justicia. Por su parte, la Constitución de 1931 opta por el sencillo título de "Justicia", en pie de igualdad con el de "las Cortes" y "Gobierno", pero sí intenta garantizar que esa justicia sea independiente, intento frustrado por las circunstancias políticas.

2 Teoría de la Constitución, Ariel, Barcelona, 1965, pág. 294. Ver en igual sentido: Garcia-Pelayo, M.: El Estado de partidos, Alianza Editorial, Madrid, 1986, pág. 129; y de Otto PARDo, I.: Derecho Constitucional. Sistema de Fuentes, Ariel, Barcelona, 1987, págs. 657 y ss. 
El artículo 117 de la Constitución desglosa el concepto de Poder Judicial, al referirse tanto a sus integrantes - jueces y magistrados-como a la función que ejercen - juzgar y ejecutar lo juzgado-3; función sometida únicamente a la Constitución y a la Ley y, en consecuencia, realizada por órganos que monopolizan la jurisdicción del Estado ${ }^{4}$ y que actúan con independencia y responsabilidad.

La independencia, base de la imparcialidad -la ley como único criterio de decisión- predicada de todos y cada uno de los jueces, se encuentra garantizada constitucionalmente a través de tres elementos esenciales:

a) La reserva de Ley Orgánica para establecer la constitución, funcionamiento y gobierno de los juzgados y tribunales, así como el estatuto jurídico de jueces y magistrados (art. 122).

b) La inamovilidad o exigencia de que los jueces y magistrados no puedan ser separados, suspendidos, trasladados ni jubilados sino por alguna de las causas y con las garantías previstas en la Ley (art. 117.2).

c) El régimen de incompatibilidades que les prohíbe desempeñar otros cargos públicos y pertenecer a partidos políticos o sindicatos (art. 127) ${ }^{5}$.

La independencia del juez ha de ser entendida - siguiendo al profesor DE OTTO- como ausencia de subordinación jurídica; es decir, que los jueces y tribunales no estén sujetos, en el ejercicio de su función, a órdenes o instrucciones de nadie, sino solamente al ordenamiento jurídico. Sin embargo, para lograr esa independencia juridica es preciso que no exista una subordinación de hecho derivada de estar sometidos sus intereses vitales a la decisión discrecional de otro poder o a la existencia de vínculos ajenos a su función. Será la exigencia de inamovilidad y el régi-

3 Ver I. DE OTto, “Poder Judicial», en J. J. González Encinar: Diccionario del sistema político español, AKAL, Madrid, 1984, págs. 654-660.

4. Exclusión de jurisdicciones no estatales y exclusión de órganos no jurisdiccionales que ejerzan la jurisdicción (el caso más claro en nuestro derecho histórico fue el control electoral parlamentario, probadamente disfuncional y que rechaza la Constitución de 1978).

5 Si bien la inamovilidad «asegura la independencia del juez frente a los demás, las incompatibilidades aseguran a los demás la independencia del juez". ALMAGRO NOSETE, J.: "Poder Judicial y Tribunal de garantías en la nueva Constitución", en Lecturas sobre la Constitución Española (coord. por T. R. Fernández), UNED, 1978, tomo l, pág. 291. 
men de incompatibilidades establecidas por Ley Orgánica, la garantía legal para ello ${ }^{6}$.

La Constitución pretende, pues, que esa independencia judicial sea efectiva $y$ no puramente nominal como lo fue tradicionalmente, y que el juez pueda ejercer su exclusiva función de juzgar y ejecutar lo juzgado sin ser perturbado por presiones externas que afecten a su carrera; para ello sustrae al Ministerio de Justicia las competencias desempeñadas a lo largo de nuestra historia constitucional en este ámbito concreto, transfiriéndolas a un órgano novedoso: el Consejo General del Poder Judicial.

Para valorar en su justa medida lo que supone la incorporación de este órgano a nuestro sistema político, es preciso partir de la auténtica realidad de la organización judicial desde la implantación del Estado Constitucional; el volver los ojos a la normativa existente a través del tiempo no significa un afán erudito o una excesiva sensibilidad históricá, sino el reconocimiento del valor que tienen los textos legales, hayan o no estado vigentes, para descubrir los problemas existentes en cada sociedad y las soluciones que se arbitraron en la situación concreta ${ }^{7}$. El absoluto sometimiento judicial al Ejecutivo fue una constante histórica, un impedimento clave para la implantación de un Estado de Derecho algo más que teórico y uno de los problemas heredados por las Constituyentes de 1978.

\section{B) LA JUSTIFICACIÓN HISTÓRICA DEL CONSEJO GENERAL DEL PODER JUDICIAL}

La España que nace en 1810 participa de la secular desconfianza de la Europa continental hacia la organización judicial. Desconfianza teórica, en primer lugar, que busca convertir la función jurisdiccional en mera función mecánica, rígidamente sometida a las previsiones legales en el marco del dogma de la plenitud del ordenamiento jurídico; esta concepción alienta en el pensamiento político de MONTESQUIEU, en la frase de ROBESPIERRE cuando afirma que el concepto de jurisdiccionalidad es incompatible con el Estado Constitucional, en el que no ha de haber más

6 Ver De Otro, I.: Estudios sobre el Poder Judicial, Ministerio de Justiciạ, Madrid, 1989, págs. 57 y ss.

7 Ver Fernández-Miranda Alonso, F.: «Monarquía y Confesionalidad», en R.D.P., n.ำ 35, UNED, 1992. 
jurisdicción que la Ley, y, por último, alcanza el cenit en la institución del "référé legislative" que obliga a los jueces a recabar del propio Parlamento la interpretación auténtica de la ley. En segundo lugar, desconfianza político-práctica, consecuencia del radical enfrentamiento entre legitimidad de origen divino y legitimidad democrática en que se produce el triunfo de la revolución liberal europea, hacia órganos procedentes del Antiguo Régimen, hostiles a aquélla. Esta desconfianza justifica las distintas regulaciones existentes hasta el último tercio del siglo que facultan al Rey para efectuar los nombramientos de los jueces sin ninguna limitación.

Será en la segunda mitad del siglo XIX cuando se inicie una revalorización de la potestad jurisdiccional iniciándose un tímido control del poder político en el ámbito electoral ${ }^{8}$ posibilitando la impugnación ante los Tribunales de las listas del censo y de las conductas delictivas de los funcionarios manipuladores del proceso electoral; igualmente se establece la intervención de los jueces en las Juntas Generales de escrutinio.

Ello obliga a elaborar normas que garanticen la independencia jurídica de la Magistratura, evitando su subordinación al Ejecutivo, normas que serán permanentemente incumplidas por éste al atribuirse el derecho a orientar e incluso influir en el proceso electoral.

8 Sin embargo, la jurisdiccionalización de los órganos contencioso-administrativos es realizada primero por los liberales en 1870 mediante la unificación de fueros y posteriormente en la Ley de la Jurisdicción contencioso-administrativa Ley Santamaría de Paredes- (1888-1894), que elimina "el último residuo del principio juguer l'administration c'est encore administrem" (GARCIA dE ENTERRÍA, E., Y T. R. FERnÁndez, en Curso de Derecho Administrativo, Civitas, Madrid, 1983, pág. 471). Pese a ello, la constitucionalización del control de la Administración no tendrá lugar hasta 1931; será el artículo 101 de la Constitución republicana el que determine que "...la ley establecerá recursos contra la ilegalidad de los actos o disposiciones emanadas de la Administración en el ejercicio de la potestad reglamentaria y contra los actos discrecionales de la misma constitutivos de exceso o desviación de podern. Pero este artículo no llevó a la reforma de la Ley de Jurisdicción Contencioso-administrativa de 1894, bajo cuya vigencia - dice el profesor Garrido Falla- «resultaba imposible impugnar una disposición administrativa de carácter general... la única defensa contra posibles ilegalidades que quedaba entonces en manos del particular era... esperar a que el reglamento ilegal fuese aplicado a su caso concreto $y$, entonces, recurrir el acto de aplicación". Es, asimismo, el precepto señalado de la Constitución de 1931 el precedente inmediato sobre la impugnación de exceso o desviación de poder en los actos discrecionales de la Administración; será la jurisprudencia del Consejo de Estado francés la que iniciará un largo camino que irá reduciendo tal discrecionalidad a límites cada vez más precisos, separando tajantemente discrecionalidad de arbitrariedad.

Garrido Falla, F.: "Artículo 106", en Comentarios a la Constitución, Civitas, Madrid, 1980, págs. 1.062 y 1.064 . 
Si bien el Ejecutivo siempre intentó controlar a los Tribunales de Justicia buscando la legitimidad de los valores que quería implantar en la sociedad, a partir del momento señalado y frente a la incipiente independencia de la Magistratura y judicialización del sistema político, esta influencia alcanzará grandes proporciones, pues precisa la legitimación de un proceso electoral manipulado desde el Gobierno. Por ello, es, quizás, en las interminables discusiones de actas publicadas en los Diarios de Sesiones del Congreso de los Diputados donde se leen las críticas más graves a la subordinación de la Magistratura a un Ejecutivo que convoca las elecciones, las gana y crea un Parlamento a su medida que inicia sús trabajos bendiciendo las mayores ilegalidades por «no suficientemente probadas" $y$, en consecuencia, rechazadas por unos jueces escogidos $y$ situados previamente por el partido mayoritario, con absoluta falta de respeto a la inamovilidad consagrada en los textos legales; a los testimonios procedentes de la Cámara voy a referirme, pues los considero eșpecialmente valiosos para detectar el estado de opinión existente sobre la teórica independencia de la Magistratura; ahora bien, estas protestas siempre proceden de la minoria, quien, cuando logra la mayoría, aplica igual concepto de Estado patrimonial y de respeto a la ley exclusivamente basado en su no derogación, que no en su cumplimiento; estas críticas sólo generan una interminable lista de disposiciones que van creando un marco normativo adecuado, en el ámbito electoral, exclusivamente inmerso en el plano del deber ser, dejando que la práctica estatal camine por derroteros cada vez más alejados de las previsiones legales ${ }^{9}$.

Con la intención de aportar más datos a la absoluta subordinación judicial señalada, conviene recordar que, desde el inicio del régimen constitucional, la norma electoral exige que cada Junta consigne en el acta, enviada posteriormente a la Cámara, las distintas reclamaciones surgidas en cada uno de los niveles del proceso. En el contenido del acta se centra el examen parlamentario y en el contenido del acta se centra la intervención del Gobierno, fiel a sus intereses electorales, a fin de que las autoridades políticas, que en esta primera fase presiden las Mesas, rechacen toda impugnación, para que la votación aparezca libre de ilegalidades y convenientemente adaptada a la norma vigente.

Las críticas continuas de los partidos que no logran el triunfo electoral sobre la no admisión de reclamaciones ${ }^{10}$ obligarán a los distintos Gobiernos a establecer medidas que garanticen el contenido del acta,

9 Me he ocupado de este tema en un trabajo sobre control electoral parlamentario; si interesa, puede verse en La verificación de poderes, UNED. 1987.

${ }_{10}$ «El Gobierno....influye en las juntas de escrutinio para que rechacen todo aquello que huela a reclamación". D. S. del Congreso, 24-II-1840, pág. 30. 
único documento con valor probatorio para la Cámara, hasta llegar a la Ley de delitos electorales de 1864, que tipifica todos los conocidos hasta el momento, relativos a la intervención de las autoridades en la elaboración del censo y en las votaciones, mediante falsificaciones, cohechos, sobornos, coacciones y violencias, y establecen una acción pública para demandar por estas conductas ante los Tribunales de Justicia. A partir de este momento, la presión del Gobierno se dirigirá no sólo a las autoridades políticas, sino a la organización judicial, para que decida a favor de sus intereses; también a partir de este momento las críticas parlamentarias sobre la dependencia judicial serán constantes y aumentarán de forma alarmante con la aplicación de la Ley Electoral de 1865, que traslada la presidencia de las Juntas de escrutinio general a los jueces de primera instancia.

Esta pretensión de aislar el proceso electoral de toda influencia gubernamental será perfeccionada en la Ley Electoral de 1890, con el inicio de una incipiente Administración Electoral cuyas decisiones podrán ser impugnadas ante los Tribunales; sin embargo, la absoluta dependencia del Gobierno de todas las autoridades del Estado hará inviable cualquier reforma.

Durante este último tercio del siglo $\mathrm{XIX}$, de interminables acusaciones parlamentarias a la presión gubernamental sobre la judicatura, existe una discusión clave que quizás resuma de forma certera el problema.

En la legislatura de 1891, el diputado republicano AZCÁRATE plantea en la Cámara las condiciones en que se encuentra la organización judicial, utilizada por el Gobierno con fines electorales, por su desgraciada dependencia del Ejecutivo; es su criterio que, mientras permanezca el Ministerio de Gracia y Justicia como representación de la Magistratura y mientras los ascensos y traslados de los jueces dependan del interés político del Gobierno, el mal será eterno y el Poder Judicial nunca será un poder. Frente a la defensa de la independencia judicial desde los textos legales ${ }^{11}$, realizada por el Ministro Fernández Villaverde, AZCÁRATE se expresa asi:

"Yo siento decir al Sr. Ministro de Gracia y Justicia que no estoy de ningún modo dispuesto a dejarme imponer con la declaración de la digni-

1 El Decreto de 24 de septiembre de 1889, de Canalejas, implanta la inamovilidad de residencia, como garantía máxima de independencia, si se hubiera cumplido. 
dad de las virtudes y de las excelencias de la magistratura... ¡Por Dios, Señores, si todos sabemos cómo están la magistratura y los jueces! Están a la altura de todos... yo creo que en toda la magistratura española, no hay un juez, ni un magistrado, y si lo hay será por casualidad, que se deje cohechar; pero creo que las cuatro quintas partes son débiles ante los halagos, los temores o las amenazas de politiquismo...." ${ }^{12}$

Estas críticas llegan al máximo nivel con motivo de la modificación establecida por la Ley Electoral de 1907, que introduce la intervención del Tribunal Supremo sobre la validez de las elecciones, emitiendo un dictamen no vinculante y dejando al Congreso la última decisión. En conșecuencia, comienza la presión del Gobierno en el propio Tribunal Supremo, a fin de lograr las mayorías necesarias; se acusa al Gobierno, en la Cámara, de otorgar la presidencia del órgano judicial a determinados Presidentes de Sala, incurriendo para ello en jubilaciones precipitadas ante las inminentes elecciones, sin respetar el orden de antigüedad exigido en la Ley electoral; se acusa al Gobierno de influir en el Tribunal para que dé al partido en el poder la mayoría necesaria, buscando los Magistrados con criterio más laxo o más amigos del Ejecutivo ${ }^{13}$. El propio Tribunal Supremo pone de manifiesto la carga que supone la Ley de 1907, que va a acabar "con los cortos visos de independencia logrados a partir de $1868^{14}$.

Esta dependencia absoluta de la Magistratura explica cómo pudo permanecer hasta 1978 una institución tan disfuncional como la verificación de poderes: trasladar el control electoral a los Tribunales significaba entregar la Cámara al Ejecutivo, en aquellos países - dice SANTAMARÍA DE PAREDES - en que no hay verdadera independencia judicial y en que la inamovilidad sólo existe como letra muerta en las leyes ${ }^{15}$.

Pese a las numerosas declaraciones constitucionales sobre la inamovilidad e independencia, el personal judicial ha dependido totalmente del Ejecutivo, quien - dice POSADA - "admite con dificultad que sus actos puedan ser revisados eficazmente por autoridad distinta de la suya" ${ }^{16}$.

12 D. S. Congreso Diputados, 20-III-1891, págs. 190 a 216.

13 D. S. Congreso Diputados, 11-I-1921, págs. 56-57; D. S. Congreso Diputados, 18-I-1921, pág. 198; D. S. Congreso Diputados, 8-VI-1923, pág. 333; D. S. Congreso Diputados, 15-VII-1919, pág. 16.

14 D. S. del Senado, 28-VII-1907, págs. 1.223 y ss. Senador Aldecoa.

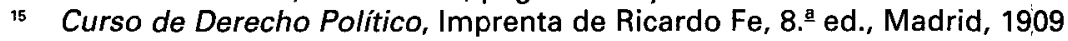
(1." ed. 1882), pág. 292. En el mismo sentido, PosADA, A.: La reforma constitucional, Librería General de Victoriano Suárez, Madrid, 1931, pág. 159; y Pérez Serrano, N.: Tratado de Derecho Político, Civitas, Madrid, 1976, pág. 777.

${ }_{16}$ Posada, A.: Tratado de Derecho Político, 4. ${ }^{\mathrm{a}}$ ed., vol. II, Librería de Victoriano Suárez, Madrid, 1929, pág. 538. 
La experiencia histórica demuestra claramente que es la inamovilidad del juez el punto fundamental en el logro de su irrenunciable independencia jurídica. No es mi intención desarrollar exhaustivamente los preceptos relativos a aquélla ni la historia interminable de órdenes y contraórdenes, siempre incumplidas, que jalonan nuestra historia constitucional; hay notables aportaciones doctrinales, en este ámbito, a las que me remito ${ }^{17}$; lo que sí pretendo es destacar algunos aspectos interesantes que se refieren al punto de partida: el modo de acceso a la Magistratura y la dependencia del órgano que lo concede. Tres son los modelos seguidos desde 1810 hasta la actualidad ${ }^{18}$ :

- Nombramiento por el Rey sin ninguna limitación.

- Nombramiento por el Rey a propuesta de altos Cuerpos del Estado.

- Ingreso en la carrera judicial por oposición.

El primer sistema extrema la dependencia del Ejecutivo y la consiguiente influencia posterior en sus funciones; es el seguido en la Constitución de 1837 (arts. 49-90), 1845 (arts. 45-90) y 1856 (arts. 52-80) y será el Ministro de Gracia y Justicia quien propondrá los nombres al Rey con absoluta discrecionalidad. Si bien la práctica va a ser la misma que en el Antiguo Régimen, su fundamento varía: ya no es el Rey el titular de la justicia, que delega en el nombrado, sino que la potestad jurisdiccional es una parte del ejercicio de la soberanía que la Constitución delega en los Tribunales que serán nombrados por el Gobierno elegido por la representación nacional; sin embargo, el origen de su nombramiento va a determinar toda su trayectoria.

El segundo modo de acceso (primero utilizado en nuestro país), si bien limita la influencia directa, no así la indirecta, según la dependencia que del Ejecutivo tengan los Altos Cuerpos proponentes. La Constitución de 1812 establece esta forma, siendo el Consejo de Estado el proponente de una terna (arts. 171-4.ำ 2.327 ); este método supone un gran avance respecto al absolutismo anterior, quizás demasiado para haber tenido éxito en ese momento histórico.

17 Montero Aroca, J.: Independencia y responsabilidad del juez, Civitas, Madrid, 1990, págs. 15 a 112; CAVERo LATAILLADE, l.: "La estructura organizativa del Poder Judicial", en AlZAGA, O.: Comentarios a las Leyes Políticas, tomo IX, Edersa, Madrid, 1987, págs. 465-476.

${ }_{18}$ Ver E. Aller: Exposición elemental teórico-histórica de Derecho Político, Librería de Victoriano Suárez, Madrid, 1875, págs. 166 y ss. 
Por último, el ingreso por oposición es el sistema más objetivo, aunque sólo alcanzará la máxima garantía en el caso de que el Ejecutivo no intervenga de forma alguna en la selección final. La Constitución de 1869 establecerá el ingreso por oposición y entre los ganadores de ésta hará el nombramiento el Rey a propuesta del Consejo de Estado; esta inicial objetividad se verá compensada por la competencia del Rey de nombrar libremente hasta la cuarta parte de Magistrados de las audiencias y del Tribunal Supremo (art. 94) por méritos ya contraídos, lo que supone en la práctica una importante discrecionalidad del Ministro de Gracia:y Justicia en los puestos más relevantes de la Magistratura. En la 1. ${ }^{a}$ República, el Real Decreto de 8 de mayo de 1873, vigente un año escaso, traslada la propuesta de nombramiento de jueces y magistrados, con carácter vinculante, al Tribunal Supremo; efímero autogobierno -dice MONTERO AROCA- ${ }^{19}$ que, sin embargo ya había sido discutido en las Constituyentes de 1869.

Será la Ley Orgánica del Poder Judicial de 1870 la que establecerá definitivamente el ingreso por oposición, exigiendo en el nombramiento el respeto al resultado obtenido en las pruebas; esta ley mantiene, sin embargo, la discrecionalidad del cuarto turno, facultad fundamental para el Gobierno, que será suprimido en el Real Decreto de 22 de enero de $1902^{20}$. Comienza en la etapa señalada el concepto funcionarial de la Magistratura, en la que se ascenderá, en principio, por antigüedad.

Sea uno u otro el sistema seguido en cada momento $y$, pese a las garantías legales, la influencia del Ministerio en todos los avatares de la carrera judicial fue total, como ya se ha señalado; las distintas normas garantizadoras de la inamovilidad del juez suponen sólo trabas legales a una decisión final del Gobierno ${ }^{21}$; con su visto bueno se iniciará la carrera judicial y de él dependerán todos sus movimientos.

Finalmente, hay que señalar que el concepto de inamovilidad se irá ampliando desde el inicio del régimen constitucional hasta llegar al contenido actual. Será regulada, en primer lugar, la limitación en la dèstitución de los jueces ${ }^{22}$; a partir de 1856, además de prohibirse toda destitución arbitraria se someten los ascensos, traslados, jubilaciones y ceses de los jueces y magistrados a los requisitos objetivos que establezca

$19^{\circ}$ Op. cit., pág. 33.

20 Montero Aroca, op. cit., pág. 34.

21 Ver en las obras citadas de Montero Aroca, J., y Cavero lataillade, 1.

22 Constitución de 1812 (arts. 52-53), Constitución de 1837 (art. 66) y Constitución de 1845 (art. 69). 
la ley ${ }^{23}$, exigiendo una decisión colectiva del Consejo de Ministros, previa consulta al Consejo de Estado, que evite la absoluta discrecionalidad del Ministerio ${ }^{24}$.

La Constitución de 1876 utiliza expresamente el término inamovilidad $^{25}$ como un elemento indisolublemente unido al status del juez: "Los magistrados y jueces serán inamovibles y no podrán ser depuestos, suspendidos ni trasladados sino en los casos y en la forma que prescribe la Ley Orgánica de Tribunales"; durante esta época el R. D. de 1889, de CANALEJAS, supuso una regulación amplia y esperanzadora sobre la inamovilidad, que la práctica política destruyó. Finalmente, la Constitución de 1931 hace especial mención a la independencia del juez en su función, no estando sometido más que a la Ley ${ }^{26}$, independencia que se pretende lograr garantizando la inamovilidad; para ello se evita la discrecionalidad total del Ministro, exigiendo, no ya la decisión del Gobierno en Consejo de Ministros, sino, y esto es importante, la intervención del Tribunal Supremo en la propuesta sobre ascensos, jubilaciones $y$ traslados de jueces y magistrados, de acuerdo con la Sala de Gobierno y los asesores jurídicos que la Ley designe entre elementos que no ejerzan la abogacía ${ }^{27}$; es preciso resaltar la influencia del republicano AZCÁRATE, quien numerosas veces en el hemiciclo del Congreso expuso como único remedio al apoderamiento del Judicial por el Ejecutivo "conferir al Tribunal Supremo o a su Presidente todas las facultades que en esta materia competan al Mịnisterio de Justicia»" ${ }^{28}$.

Si las circunstancias políticas de este país no hubieran llevado al fracaso todo intento de juridificar el Estado, esta regulación podría señalarse como el paso natural anterior a la legislación actual, que intenta lograr esa independencia jurídica de la Magistratura asentada, en primer lugar, en una auténtica inamovilidad que no pueda depender de la decisión del Ejecutivo, como la práctica política ha demostrado durante 150 años y que justifica plenamente la creación de un órgano novedoso como es el Consejo General del Poder Judicial.

23 Constitución de 1856 (art. 70.2); pese a su no vigencia, se recoge el concepto existente en ese momento.

${ }^{24}$ Constitución de 1869 (arts. 95 y 97).

25 Artículo 80.

26 Artículo 94.

27 Artículo 97, b.

28 D. S. Congreso Diputados, 20-III-1891, págs. 190 a 216, cit. Opinión recogida en su obra El régimen parlamentario en la práctica, Ed. Sobrinos de los sucesores de M. Minuesa de los Ríos, Madrid, 1931, pág. 128. 


\section{C) EL CONSEJO GENERAL DEL PODER JUDICIAL EN LA CONSTITUCIÓN DE 1978}

A través de lo dicho hasta ahora se ha visto cómo la organización judicial ha seguido desde el último tercio del pasado siglo un modelo funcionarial, que supone un ingreso por oposición y una carrera basada en la antigüedad y los méritos, que se desarrolla a través de nombramientos, traslados, ascensos, jubilaciones y un control disciplinario mediante sanciones ${ }^{29}$. Tradicionalmente fue el Ministerio de Justicia quien tenía competencia para decidir sobre la situación profesional de estos funcionarios y sobre la dotación de medios necesarios para ejercer la potestad de juzgar y ejecutar lo juzgado. Pese a las regulaciones contempladas en los distintos textos para evitar una decisión discrecional del Ministerio en este ámbito de la llamada carrera judicial, lo cierto es que el sometimiento de la justicia al Gobierno fue total, con lo que supone de incidencia en esa independencia jurídica que el juez ha de tener. La Constitución actual ha buscado una solución a este problema —crucial para que el Estado de Derecho sea efectivo- encomendando el gobierno del Poder Judicial a un órgano ajeno al Ejecutivo, de forma que cada juez - de quien se predica la independencia- esté sometido exclusivamente al ordenamiento jurídico y no a las órdenes del Gobierno.

Existen dos posiciones doctrinales sobre el tipo de gobierno quie ha de realizar este órgano: bien la que pretende un autogobierno absoluto entendido como gestión autónoma de todos los medios personales $y$ materiales ${ }^{30}$, o bien la mayoritaria que defiende un autogobierno relativo, sobre los aspectos que inciden directamente en la carrera del juez -ascensos, traslados, jubilaciones, disciplina-, y que pueden crear una situación de hecho incompatible con la deseada independencia jurídica, pero dejando la dotación material del Poder Judicial en manos del Gobierno, responsable último del funcionamiento de la justicia ${ }^{31}$. Ésta es la

29 Ver Almagro Nosete, J.: «Poder judicial y Tribunal de Garantias en la nueva Constitución", en Lecturas sobre la Constitución Española (coord. T. R. Fernández), UNED, 1978, pág. 295.

30 Ver F. C. SÁINZ DE Robles: «EI Consejo General del Poder Judicial como órgano constitucional", en Jornadas de Estudio sobre el Consejo General del Poder Judicial, Madrid, Editora Nacional y CGPJ, 1983; "Poder judicial y Consejo Generăl del Poder Judicial", en Estudios sobre la Constitución Española, Homenaje al prọfesor E. García de Enterría, tomo IV, Civitas, Madrid, 1991.

31 Ver, entre otros, Torres del Moral, A.: Principios de Derecho Constitucional, Átomo, tomo II, Madrid, 1988, pág. 296; XıL Ríos, J. A.; González Rivas, J. J., y Rodríguez-Zapata, J.: "El Poder Judicial y su Consejo General en el Estado social y democrático de Derecho", en Poder Judicial (Premios Poder Judicial, I.), CGPJ, Mạdrid, 1990, pág. 17. 


\section{posición adoptada por la Constitución Española y la seguida en el Dere- cho Comparado ${ }^{32}$.}

Aunque en nuestro derecho histórico no existe un antecedente exacto de este órgano, si que se percibe la necesidad de aislar el Poder Judicial de toda influencia que pueda afectar a la esfera vital del juez y obligarle a juzgar de acuerdo con órdenes más o menos expresas del Gobierno y no con imparcialidad, siendo la ley el único criterio de decisión.

32 Nuestros Constituyentes, deseosos de encontrar la solución a uno de los múltiples problemas que llegaron sin resolver a la actualidad, observaron la regulación establecida en la Constitución italiana de 1947, influida a su vez por la francesa de 1946; Italia crea un Consejo Superior de la Magistratura que recoge las competencias tradicionalmente asumidas por el Ministerio de Justicia; el artículo 104 señala sus principios esenciales y remite a ley posterior su desarrollo (Leyes de 24 de marzo de 1958 y de 16 de septiembre de 1958, modificadas por Ley de 16 de marzo de 1967). Este órgano, de naturaleza polémica, denominado constitucional por BISCARETTI y de mera relevancia constitucional por VIRGA, se le ha dado especial relieve al ser presidido por el Presidente de la República, quien, en un sistema parlamentario monista como es el italiano hasta el momento, es un poder por encima del Ejecutivo que representa la unidad nacional. Está compuesto (art. 104 e) por dos tipos de miembros: por derecho propio -Presidente de la República y Presidente y Fiscal General del Tribunal Supremo-y 21 miembros electivos - dos tercios se elegirán por todos los Magistrados ordinarios pertenecientes a las distintas categorías y un tercio por el Parlamento, entre profesores numerarios de materias jurídicas y abogados que cuenten con más de 15 años de ejercicio profesional; el Vicepresidente será nombrado por el Consejo entre los vocales elegidos por el Parlamento. La independencia de estos vocales respecto de sus electores se garantiza mediante un mandato de 4 años, continuando en funciones hasta que sea renovado el órgano, la prohibición de reelección inmediata e importantes incompatibilidades-. Este órgano asume tres tipos de competencias: de propuesta (sobre materias que afecten a la Administración de Justicia), consultivas (sobre proyectos de ley en igual ámbito) y decisivas (sobre el status del juez) a petición del Ministro de Justicia, quien puede intervenir en las reuniones del órgano pero no en las deliberaciones. La Constitución señala expresamente, en el artículo 105, las referentes a admisión, nombramiento, traslados, ascensos y medidas disciplinarias. La distribución de los medios instrumentales con los que ha de contar la Magistratura siguen correspondiendo al Ministerio. Esta regulación ha sido criticada por distintos autores; según MARIANINI, la Ley de desarrollo ha devaluado el Consejo "a nivel de órgano administrativo... está directamente condicionado por el Ministerios; a su vez, MoRTATl critica su progresiva politización, consecuencia de la partitocracia italiana, "dándose la paradoja de que un órgano creado para garantizar la independencia de la Magistratura deriva en un potente instrumento de politización".

P. BiscaretTI DI Ruffia: Derecho Constitucional (trad. P. Lucas Verdú), Tecnos, Madrid, 1973, pág. 511.

P. VIRGA: Diritto Costituzionale, 7.a ed., Giuffrè, Milano, 1971, pág. 648.

G. MaraninI: "L'Italie", L.G.D.J., París, 1961, pág. 69.

C. Mortati: Istituzioni di Diritto Publico, II, 9.a ed., Cedam-Padova, 1969, pág. 1.283 . 


\section{Características generales}

\section{Artículo 122:2:}

"El Consejo General del Poder Judicial es el órgano de gobierno del mismo. La ley orgánica establecerá su estatuto, y el régimen de incompatibilidades de sus miembros y sus funciones, en particular en materia de nombramientos, ascensos, inspección y régimen disciplinarion.

El Consejo General del Poder Judicial es un órgano de naturaleza polémica, cuyo desarrollo normativo exige ley orgánica y que tiene como función el gobierno del Poder Judicial para garantizar la independencia jurídica de cada uno de sus componentes - jueces y magistrados-en el ejercicio de la potestad jurisdiccional - juzgar y ejecutar lo juzgado-; su creación supone el reconocimiento de la importancia que tienen las funciones administrativas que ejerce para que la organización judicial sea un: poder del Estado de Derecho.

a) La opinión doctrinal sobre su naturaleza no es pacífica, sino que, mientras una parte de la doctrina lo califica de órgano constitucional ${ }^{33}$, para otro sector el mero órgano de relevancia constitucional ${ }^{34}$. Siguiendo el criterio del profesor GARCÍA-PELAYO sobre los elementos que ha de reunir un órgano para ser calificado de constitucional ${ }^{35}$, destaco el que se refiere a que la propia Constitución «determina su composición, los órganos y métodos de designación de sus miembros, su status constitucional y su sistema de competencias", para concluir en su mera relevancia constitucional - pese a los arts. 59 y 71.1 de la LOTC-, puesto que el método de integración de sus miembros ha sido dejado al legislador ordinario, entendiendo el Tribunal Constitucional que es válida la opción de la Ley Orgánica del Consejo General del Poder Judicial de 1980 y la de la Ley Orgánica del Poder judicial de 1985, posibilitando, incluso, otras futuras ${ }^{36}$; a ello hay que añadir el giro dado por esta última regulación sobre el ámbito de competencias del Consejo frente a las expectativas -infundadas, a mi modo de ver- despertadas por la regula-

33 Ver Diez Picazo, L. M.: Régimen Constitucional del Poder Judicial, Civitas, Madrid, 1991, págs. 132-133; XıL Rios, J. A., y otros, op. cit., pág. 22.

34 Terol Becerra, M. J.: El Conseio General del Poder Judicial, CEC, Madrid 1990, págs. 141-154; Garcia-RoCA, J.: El conflicto entre órganos constitucionales, Tecnos, Madrid, 1987, págs. 69 y ss.

y 13.

${ }^{35}$ "El status del Tribunal Constitucional», en REDC n.o 1, 1981, págs. 12.

36 STC 108/1986, de 29 de iulio («B.O.E." de 13 de agosto de 1986). 
ción anterior. Se pueden señalar otros dos criterios que avalan lo dicho: sus competencias exclusivamente administrativas - siguiendo a Vir$\mathrm{ga}^{37}-\mathrm{y}$ el hecho importante de que esas mismas competencias sean controlables por la jurisdicción ordinaria. Todo ello lo califica de órgano de relevancia constitucional con funciones administrativas; el único argumento que sostiene la naturaleza constitucional del Consejo es, como se ha dicho, la Ley Orgánica del Tribunal Constitucional, y mientras su artículo 59 siga vigente, el Consejo será tal formalmente; sin embargo, esta regulación responde a una interpretación inicial, recogida en la Ley Orgánica de 1980, que la práctica política y el propio Tribunal Constitucional se encargarán de modificar. Como resumen se puede decir que, a través de las dos regulaciones existentes hasta el momento, varía totalmente la fisonomía del Consejo.

b) El Consejo no forma parte del Poder Judicial, integrado exclusivamente por juecés y magistrados, ni ejerce funciones jurisdiccionales, juzgar y ejecutar lo juzgado, sino que es un órgano que garantiza la independencia jurídica de aquél, aislando de los otros poderes toda decisión sobre el status profesional de jueces y magistrados, que incida en la independencia necesaria en un Estado de Derecho.

c) Como consecuencia de lo anterior, no es la instancia superior de ningún órgano judicial ${ }^{38}$, ni será el representante de este Poder, según aclara el Tribunal Constitucional ${ }^{39}$; por el contrario, la Ley Orgánica del Poder Judicial atribuye al Presidente del Tribunal Supremo y del Consejo la representación del Poder Judicial y de su órgano de gobierno ${ }^{40}$.

d) Su ámbito de actuación será todo el territorio nacional; a él estarán subordinadas las Salas de Gobierno del Tribunal Supremo, de la Audiencia Nacional y de los Tribunales Superiores de Justicia ${ }^{41}$.

e) La Constitución establece un mínimo de competencias del Consejo en materia de nombramientos, ascensos, inspección y régimen disciplinario de jueces y magistrados; es decir, competencias que afecten al ámbito en el que tradicionalmente influyó el Ejecutivo a fin de tener subordinada a la organización judicial. No conviene perder de vista esta pretensión histórica, nunca efectiva, a la hora de tratar el aspecto competencial del nuevo órgano, cuya creación y posterior desarrollo por la

Op. cit., loc. cit.

TORRes del Moral, A.: "Principios...", cit., pág. 296.

STC. 45/1986, de 17 de abril («B.O.E." de 29 de abril).

Artículo 105 LOPJ.

Artículo 104 LOPJ. 
Ley Orgánica del CGPJ de 10 de enero de 1980 originó una serie de optimistas expectativas no respaldadas ni por los modelos existentes ni por el contenido del problema existente en nuestra propia historia.

La Constitución no explicita en ningún momento la atribución al Consejo de los medios materiales que precisa el Poder Judicial como infraestructura, cuya gestión, según el esquema teórico de nuestro sistema político, corresponde al Gobierno; a éste compete, según el artículo 97 de la Constitución, la dirección de la política interior, de la que responderáá ante el Parlamento ${ }^{42}$.

f) Todas las competencias del Consejo, como ya se dijo, son administrativas y controlables por la jurisdicción de lo contencioso-administrativo ante la Sala correspondiente del Tribunal Supremo ${ }^{43}$; la Ley Orgánica de 1980, curiosamente, residenciaba esta competencia en el Pleno del Tribunal Supremo ${ }^{44}$. Cada criterio parece responder al concepto que sobre el Consejo tuvieron los redactores de una y otra norma.

\section{Competencias}

Las competencias del Consejo, reguladas mediante la Ley Orgánica del Poder Judicial de 1 de julio de 1985, se pueden desglosar de la siguiente forma ${ }^{45}$ :

a) Nombramientos. Propuesta, por mayoría de 3/5, para el nombramiento del Presidente del Tribunal Supremo y del Consejo, decidida por todos los Vocales de éste, y que habrá de recaer en persona ajena al órgano constituido ${ }^{46} \mathrm{y}$ perteneciente a iguales ámbitos profesionales que

42 Ver Diez-Picazo, L. M.․: op. cit., pág. 148.

43 Artículo 143 LOPJ de 1 de julio de 1985 y artículo 58.

44 Artículo 47 LOCGPJ de 10 de enero de 1980.

45 Ver sobre esta materia TeRol BeCERRA, M. J., op. cit., págs. 101-135.

46 La ley no prohíbe expresamente que el nombramiento de Presidente recaiga en uno de los vocales; sin embargo, la regulación de la elección de Vicepreșidente en el artículo 104, "propuesto por el Pleno de éste entre sus vocales", y la utilizada en la Ley Orgánica del Tribunal Constitucional respecto a la elección de Presidente (art. 9), "elige de entre sus miembros...", condujo a interpretar que, en este supuesto, el Presidente no sea un miembro del órgano; de todas formas, y al no estar prohibido, en el caso de que así fuera, se producirá un cese anticipado dèl vocal y se instará a la Cámara de procedencia a que efectúe una nueva propuesta (art. 116 LOPJ). 
el resto de los componentes ${ }^{47}$. Este nombramiento se llevará a cabo mediante Real Decreto refrendado por el Presidente del Gobierno. Nombramiento mediante orden de los jueces y presentación a Real Decreto - refrendado por el Ministro de Justicia- de los nombramientos de Magistrados del Tribunal Supremo, Presidentes y Magistrados.

Estos nombramientos han tenido una regulación diferente en la Ley Orgánica del Consejo de 1980 y en la Ley Orgánica del Poder Judicial de 1985, en dos aspectos, que responden a la concepción que sobre el órgano se tiene en una y otra norma. En primer lugar, la antigua ley las declaraba competencias decisorias, lo que no hace la actual; sin embargo, lo son, en cuanto a facultades expresamente establecidas en la Constitución, como especialmente defendidas de la intervención de otros poderes. En segundo lugar, respecto a la forma jurídica que asumirán tales nombramientos, Real Despacho y Real Orden en la Ley Orgánica de 1980 (arts. 2 y 27), Orden y Real Decreto en la vigente (arts. 107 y 123), a través de la forma exigida en la actualidad se deja claro, frente a interpretaciones anteriores, cómo el responsable de la justicia, como ámbito de la política interior, es el Gobierno, respetando aquellas competencias del Consejo que afectan al estatuto jurídico de jueces y magistrados: nombramientos, ascensos, inspección y régimen disciplinario.

Propuesta para el nombramiento de los miembros correspondientes del Tribunal Constitucional cuando así proceda, adoptada por mayoría de 3/5 de los Vocales; el Tribunal, según el artículo 10, f), de su Ley Orgánica, verificará el cumplimiento de los requisitos exigidos para el nombramiento de sus miembros, verificación formal que se refiere a la procedencia y calidad profesional de los Magistrados y a la ausencia de incompatibilidades.

Nombramiento de Secretario General y miembros de los Gabinetes o Servicios dependientes del Consejo; competencia que incide directamente en la organización interna del órgano, base de su autonomía.

Finalmente, el Consejo será oído antes de efectuar el nombramiento de Fiscal General del Estado (art. 108.4), sin que su criterio sea vinculante para el Gobierno.

b) Inspección de Juzgados y Tribunales (art. 107.3), competencia que amplía la potestad disciplinaria sobre jueces y magistrados que le reconocía la Ley Orgánica de 1980 y posibilita una mejor información del órgano respecto al funcionamiento de la organización judicial y el cum-

47 Ver Cavero latalllade, I., op. cit., pág. 523. 
plimiento de los deberes de su personal. La iniciativa de inspección corresponde al Consejo, si bien puede ser instado por el Ministerio de Justicia (arts. 171 a 177 LOPJ). Su ejercicio dará al Consejo un conocimiento privilegiado sobre la realidad judicial.

c) Formación y perfeccionamiento, provisión de destinos, ascensos, situaciones administrativas y régimen disciplinario de jueces y magistrados (art. 107.4); éste es el núcleo esencial que afecta a la situación personal del juez y en el que tradicionalmente intervino el Gobierno; es a su vez, junto a los nombramientos, el mínimo competencial exigido por la Constitución al órgano de gobierno del Poder Judicial.

La Ley Orgánica del Consejo de 1980 atribuía al órgano, además de las competencias reconocidas actualmente, la selección de jueces y magistrados y la selección, formación y perfeccionamiento, incluida la aprobación de programa y nombramiento de Tribunal para las pruebas de acceso, del personal auxiliar y colaborador de la Administración de Justicia (art. 2.6.o). La vigente ley reduce sensiblemente estas competencias, que pasan a manos del Ministerio de Justicia ${ }^{48}$. Respecto a la selección de jueces y magistrados ${ }^{49}$ se establece una coparticipación de funciones, con mayor importancia del Ministerio de Justicia, distribuidas de la siguiente forma: las normas por las que ha de regirse el acceso al Centro de Estudios Judiciales (oposición), los ejercicios y los programas, se aprobarán por el Ministerio, oídos el Consejo y el propio Centro (art. 306 LOPJ).

El Tribunal de acceso al Centro de Estudios Judiciales será nombrado por el Consejo y estará presidido por el Presidente del Tribunal Súpremo o Magistrado del mismo órgano judicial en quien delegue aquélie integrado por seis Vocales nombrados a propuesta del Consejo de Universidades (dos Catedráticos de disciplinas jurídicas), el Ministro de Juşticia (un Letrado del Estado), el Consejo General de la Abogacía (un abogado en ejercicio), el Fiscal General del Estado (un Fiscal) y el Consejo General del Poder Judicial (un Magistrado) (arts. 304 y 305 LOPJ).

Por tanto, el acceso a la carrera judicial no es competencia exclúsiva del Consejo, sino compartida con el Gobierno, quien vuelve a apo-

48 Decisión contestada desde diferentes sectores con el argumento de que el alejamiento de este personal del ámbito de influencia del Gobierno contribuye, aunque sea de forma indirecta, a esa independencia jurídica del juez, esencia de un Estado de Derecho. DíEz-PiCAzo lo considera "garantía añadida a la independencia de la propia judicatura", op. cit., págs. 146-147.

${ }_{49}$ El modo de acceso a la carrera judicial consiste en la superación de una oposición libre entre licenciados en Derecho, completada con la aprobación de un curso en el Centro de Estudios Judiciales y de prácticas en un Tribunal. 
derarse del importante tema relativo al programa de oposiciones ${ }^{50}$. Sin embargo, el punto conflictivo históricamente fue el desarrollo de la oposición y la decisión final sobre ésta; actualmente queda en manos de un Tribunal nombrado por el Consejo pero en cuya composición intervienen distintas instancias y el Ministerio, éste en una proporción mínima directamente pero muy importante indirectamente, pues la mayoría de los organismos que nombran los Vocales dependen del Gobierno.

Superadas las pruebas de oposición libre, el curso que ha de realizarse en el Centro de Estudios Judiciales dependerá de las directrices marcadas por el Ministerio de Justicia, ya que, el Centro de Estudios Judiciales está concebido de la siguiente forma:

- Es una entidad de derecho público con personalidad jurídica propia dependiente del Ministerio de Justicia (art. 434 LOPJ). Es el Ministerio de Justicia quien nombra a su Director, a diferencia de la regulación anterior, que atribuía esta competencia al Consejo (art. 2-8. L.O. 1980).

- Los aspirantes que superen el Curso y las prácticas en un órgano jurisdiccional serán nombrados jueces por el Consejo General del Poder Judicial, según el orden de la propuesta hecha por el Centro de Estudios Judiciales (art. 307 LOPJ).

Por el contrario, en el supuesto de promoción de juez a magistrados, las pruebas y programas se aprobarán por el Consejo, oído el Centro de Estudios Judiciales (art. 312 LOPJ). Es decir, la actual ley establece una separación entre el ingreso en la carrera, en el que interviene el Ministerio de Justicia en gran medida, y la promoción en aquélla, competencia del Consejo, como supuesto englobado en el principio de inamovilidad, base fundamental de la independencia. Sin embargo, está demostrado a través de nuestra larga y accidentada historia constitucional que el Gobierno siempre intentó controlar el acceso a la carrera judicial como punto de partida en la permanente influencia en la Magistratura, lo que justifica la reivindicación que sobre esta competencia se ha hecho desde distintos sectores.

50 Tema muy contestado en la discusión parlamentaria sobre la ley orgánica. El Grupo Parlamentario Socialista, mayoritario en la Cámara, parte de que el opositor a juez no es tal; por tanto, esta fase no corresponde al Consejo, sino que la decisión sobre las materias que estudie es facultad irrenunciable del Estado: Ley Orqánica del Poder Judicial. Trabajos parlamentarios, Cortes Generales, Madrid, 1986, pág. 7400 (13-XI-1984). 
Esta ley regresa al tan denostado históricamente cuarto turno, siempre puerta abierta a la intervención del Ejecutivo; con la justificación manifestada en la Exposición de Motivos de que es necesario recurrir a mecànismos complementarios para que la sociedad española se dote del número necesario de jueces y magistrados y se abra a otros campos jurídicos, se prevé un sistema de acceso a la carrera judicial de juristas de reconocido prestigio. Estas plazas serán convocadas por el Ministerio de Justicia, quien aprobará y publicará las correspondientes bases en las quie se gradúa la puntuación de los méritos, dentro del baremo expresado en la Ley (art. 313 LOPJ); el Tribunal que juzgará será nombrado por el Consejo en la misma forma y con los mismos componentes que en la oposición libre (art. 314 LOPJ); al comentario hecho respecto a ésta me remito.

d) Materia presupuestaria. La gestión económica de los medios necesarios para que la organización judicial funcione, lo mismo que el control económico del Consejo, corresponde al Gobierno, que en ningún momento renunció a ella; ni el Gobierno de Unión de Centro Democrático, a través de la Ley de 1980, ni el Gobierno Socialista, mediante la regulación de 1985. La Ley Orgánica del CGPJ de 1980 lo establecía claramente en su artículo 6: "...Corresponde al Gobierno, a través del Ministerio de Justicia, proveer a los juzgados y tribunales de los medios precisos para el desarrollo de su función con independencia y eficacian; en igual sentido se expresa la Ley Orgánica vigente (art. 37.1).

En ambas leyes ${ }^{51}$ se deja al Consejo una competencia mínima, como es la elaboración y aprobación del anteproyecto de presupuesto del mismo, que remitirá al Gobierno; este anteproyecto no es vinculante, sino que servirá de orientación a la decisión del Gobierno.

Mientras que es lógica dentro del sistema político existente en nuestro país, la reserva por el Gobierno de los medios materiales atribuidos a la Justicia, como un aspecto más de la política interior de la que es responsable, no lo es tanto el sometimiento total del presupuesto del Consejo a la última decisión del Gobierno, a diferencia de lo exigido al Tribunal Constitucional; pienso que es otro argumento que avala la simple relevancia constitucional del Consejo General del Poder Judicial, a diferencia de la existencia de presupuestos integrados en los Generales del Estado por parte del Tribunal Constitucional o de la Corona. Este control férreo por parte del Ejecutivo es uno de los puntos que envenenan las relaciones Ejecutivo-Judicial y dan pie a las acusaciones de prepotencia de aquél que se oyen y leen en los medios de comunicación social.

51 Artículo 2.9. ${ }^{5}$ de la LOCGPJ de 1980, y artículos 107.8 y 127.12 de la LOP'J de 1985. 
e) Propuesta en relación a normas legislativas. La ambigüedad en la redacción de la Ley Orgánica de 1980 (art. 3.) sobre facultades de iniciativa, propuesta e informe, llevó a determinados sectores doctrinales ${ }^{52}$ a polemizar sobre la existencia de iniciativa legislativa del Consejo en materia judicial; expectativa que no se corresponde con lo establecido en el artículo 87 de la Constitución y en el artículo 108 del Reglamento del Congreso de los Diputados, que no señala al Consejo entre los organismos a quienes corresponde tal iniciativa ${ }^{53}$.

La regulación actual establece claramente en el artículo 108 que el Consejo General del Poder Judicial deberá informar los anteproyectos de leyes y disposiciones generales en relación con las siguientes materias: demarcaciones judiciales, plantilla orgánica de jueces, magistrados, secretarios y personal al servicio de la Administración de Justicia; estatuto orgánico de jueces, magistrados, secretarios y personal al servicio de la Administración de Justicia, normas procesales y otras que afecten a la constitución, organización, funcionamiento y gobierno de los juzgados $y$ tribunales y régimen penitenciario. Lo que se deduce de la redacción es que este informe es obligatorio para el Consejo, va dirigido al Gobierno y no es vinculante para éste, quien deberá remitirlo a las Cortes cuando se trate de anteproyectos de ley.

Algunos autores han criticado la "cicatería" de la ley al privar al órgano de gobierno de proponer al Ejecutivo, con independencia de su aceptación posterior, "la adopción de proyectos de ley en las materias cuyo gobierno les compete ${ }^{54}$. Esta opinión es razonable, ya que el Consejo es quien posee mejor información sobre las necesidades existentes en el ámbito de la justicia, lo que podría ser un interesante punto de partida para la elaboración del anteproyecto, además de otorgar a la institución una relevancia importante en todo lo que puede afectar al ejercicio de sus competencias; es decir, sería razonable la colaboración del Consejo en la fase pre-legislativa, incluso comenzando el proceso ante el Gobierno, quien, como titular real de la iniciativa, podría rechazarla o aceptarla e incorporarla al anteproyecto; más de esto no es posible en la regulación constitucional sobre la iniciativa legislativa, taxativamente reservada al Gobierno, al Congreso y al Senado, a las Asambleas Legislativas de las Comunidades Autónomas y al cuerpo electoral.

52 Ver Carretero Pérez, A.: «Precisiones sobre las facultades de iniciativa del Consejo General del Poder Judicial", RAP, n.o 101-102, 1983; y "La potestad reglamentaria y la iniciativa legislativa del CGPJ", en Jornadas de Estudio sobre el CGPJ, cit., pág. 763.

53 Ver Xiol Ríos, J. A., y otros, op. cit., pág. 57.

54 Ver XIOL Ríos, J. A., y otros, op. cit., pág. 60. 
f) Potestad reglamentaria. Es éste uno de los aspectos más polémicos en relación a las competencias del Consejo, debido a las esperaṇzas despertadas por la regulación de $1980^{55}$, asumidas y desarrolladas por el primer Consejo ${ }^{56}$. La citada ley establecía en el artículo 5 que rel CGPJ podrá dictar reglamentos sobre su organización y funcionamiento, así como sobre el régimen de personal y servicios y demás materias de su competencia dentro del ámbito de la presente ley». La propia redacción del precepto generó las expectativas señaladas, respaldadas entonces por los grupos parlamentarios mayoritarios. Se reconoce la potestą interna, que no presenta ningún tipo de dificultad teórica, y se vislumbra una posible potestad reglamentaria externa en las materias de su competencia (muy amplia en la citada ley), defendida desde algunos sectores como implícita a la calidad del Consejo como órgano de gobierno de lós jueces y magistrados ${ }^{57}$.

Desde posiciones contrapuestas, una mayoria doctrinal considera que la potestad reglamentaria corresponde exclusivamente al Gobiernio según el enunciado del artículo 97 de la Constitución, partiendo del essquema teórico del Estado democrático de derecho, que exige responsábilidad política, directa o indirecta, ante el cuerpo electoral, a todo aquel órgano que elabora normas ${ }^{58}$.

55 Esta ley fue elaborada, con un amplio consenso parlamentario, con la finalidad de dotar al Consejo de amplias competencias cercenadas al Ministerio de Justicia, concediéndole un autogobierno que, como escribiría I. DE OTTo, «no tiene parangón en el derecho comparado ni aceptación doctrinal»; personas relevantès del Partido Socialista defienden en ese momento la iniciativa legislativa y la potestad reglamentaria externa e interna del Consejo, abjurando pocos años después de este criterio; en descargo de estas posiciones tan mudables se podría recordar la especial sensibilidad - puramente teórica- hacia los problemas históricos heredados, sin haberlos contrastado aún con la práctica política.

I. DE OTto: "Consejo General del Poder Judicial», en González Encinar, J. J., Diccionario del sistema político español, AKAL, Madrid, 1984, pág. 111.

Ledesma Bartret, F.: «Relaciones entre el CGPJ y el Poder Ejecutivo", en Jornadas de Estudio sobre el Conselo General del Poder Judicial, CGPJ y Editora Nacional, Madrid, 1983, págs. 504 y ss.

Cavero Lataillade, I., op. cit., pág. 517.

56 Ver Diez-Picazo, L. M., op. cit., pág. 149; Montero Aroca, J.: "Poder Judicial y Administración de Justicia en la Constitución y en la práctica», en Álvarez CoNDE, E.: Diez años de régimen constitucional, Tecnos, Madrid, 1989, pág. 321. En este trabajo recuerda cómo el primer Consejo dictó acuerdos que modificaron reglamentos pre-constitucionales sobre la Escuela Judicial, secretarios judiciales, oficiales, auxiliares, agentes y carrera judicial (especialmente sobre los ejercicios de oposiciones).

57 Carretero Pérez, A., op. cit., pág. 763, entiende que el CGPJ tiene potestad reglamentaria externa en toda materia de su competencia.

${ }_{58}$ Ver Díez-Picazo, L. M.a op. cit., pág. 150, y, aún vigente la Ley Orgánica de 1980, Castedo Álvarez, F.: "La potestad reglamentaria del Consejo General del Poder 
El artículo 110 de la vigente Ley Orgánica dice que "El Consejo General del Poder Judicial podrá dictar Reglamentos sobre su personal, organización y funcionamiento en el marco de la legislación sobre la función públican; es decir, reconduce la competencia a la potestad reglamentaria ad intra, que tiene todo órgano autónomo y que afecta a su propia organización interna, eliminando la ambigüedad anterior y las esperanzas creadas en el primer Consejo. Además, la Disposición Adicional primera, 2, dice que uel Gobierno aprobará los Reglamentos que exige el desarrollo de la presente Ley Orgánica», lo que supone la reconducción de esta discutida competencia al Ejecutivo.

La polémica será zanjada por la Sentencia 108/1986, de 29 de julio, que resuelve el recurso presentado por $D$. José M. Ruiz-Gallardón, comisionado por 53 Diputados, contra la totalidad de la Ley Orgánica 6/1985, por vicios de procedimiento $y$, subsidiariamente, contra determinados preceptos, entre ellos el que se refiere a la citada Disposición Adicional, por violación del artículo 122.2 de la Constitución, en relación al 117 de la misma, toda vez que atribuye al Gobierno la potestad reglamentaria para el desarrollo de la Ley Orgánica, sin reconocer - dicen los recurrentes- la potestad que en este punto corresponde al Consejo en virtud de los poderes implícitos que entrañan las funciones que le atribuye la Norma Suprema.

El Tribunal Constitucional rechaza tales poderes implícitos, ratifica la potestad reglamentaria ad intra - admitida pacíficamente por la doctrina- en pie de igualdad con la que la Ley Orgánica del Tribunal Constitucional reconoce a éste para su propia organización y reconduce la potestad reglamentaria externa a un punto medio muy interesante.

En primer lugar, entiende que uno de los elementos que garantizan la independencia del poder judicial - valor exigido directamente en la Constitución - es la reserva de Ley Orgánica para toda regulación que afecte al conjunto de derechos y deberes de la Magistratura; esa salvaguardia impide también que el desarrollo de ese estatuto quede en manos del Gobierno ${ }^{59}$.

En segundo lugar, en ningún momento - dice la Sentencia- la regulación reglamentaria del Gobierno puede incidir en el conjunto de de-

Judicial», en El Poder Judicial, vol. I, Madrid, I.E.F., 1983, págs. 790-807, resaltando la necesidad de autonomía del Consejo para evitar las interferencias del Ejecutivo, como justificación de la potestad reglamentaria interna.

59 Medio utilizado tradicionalmente por el Ejecutivo para obviar lo establecido en la ley; ver Terol BeCerra, M. J., op. cit., págs. 132 y ss. 
rechos y deberes que configuran el status de los jueces y sí sólo regular condiciones accesorias para su ejercicio; es decir, el Tribunal Constitucional reconoce una potestad reglamentaria ad extra preferente al Consejo para desarrollar la Ley Orgánica en aquello que afecte al mínimo establecido constitucionalmente: nombramientos, ascensos, inspección y régimen disciplinario. Esta potestad tiene su origen, pues, en la propia Constitución, y su justificación en la práctica política existente en todo nuestro régimen constitucional histórico.

Al Gobierno corresponderá, de forma secundaria, la elaboración de normas que afecten a las condiciones accesorias para el ejercicio de los deberes y derechos aludidos.

Por último, si el poder reglamentario del Gobierno incide en el ámbito reservado al Consejo que garantiza la independencia judicial - valor constitucional prioritario-, podrá ser impugnado ante la jurisdicción de lo contencioso-administrativo; si es el Consejo el que amplía sus atribuciones fuera del círculo especialmente garantizado, podrá ser impugnado ante la misma instancia.

Por tanto, el Tribunal rechaza la atribución al Gobierno de toda regulación en desarrollo de la Ley, considerando que es compartida por ambas instancias, de acuerdo con la interpretación señalada ${ }^{60}$. Sigue siendo la independencia judicial el punto de referencia en toda valoración sobre su órgano de Gobierno; todo aquello y sólo aquello que pueda incidir en ella debe ser reservado; lo demás son imaginaciones ${ }^{61}$. Un régimen constitucional que pretenda someter a Derecho todas las relaciones de poder ha de garantizar la independencia jurídica de los Tribunales de Justicia, como Poder del Estado independiente de cualquier influencia; esta influencia a lo largo de la historia pudo llevarse a cabo por órdenes directas del Ejecutivo, en un principio, pero según se van perfeccionando las garantías legales, a través de órdenes indirectas y regulaciones reglamentarias que afectan al ámbito vital del juez, lo que le obliga a mantener determinados criterios si quiere preservar su carrera profesional; como decía en el Congreso el Diputado AZCÁRATE, "yo creo que en lạ

60 A. Porras Nadales habla de "rechazo de un eventual monopolio" para el desarrollo normativo de la ley, atribuido bien al Consejo, bien al Gobierno: «El Conisejo General del Poder Judicial, según la STC 108/1986, de 29 de julio, sobre la Ley Orgánica del Poder Judicialı, en REDC, n. 19, 1987, pág. 240.

61 El artículo 14 de la LOPJ atribuye al Consejo «la defensa activa de la independencia judicial" al señalar que "los jueces o magistrados que se consideren inquietados o perturbados en su independencia lo pondrán en conocimiento del Consejo General del Poder Judicial"; sin embargo, no se arbitran mecanismos concretos para llevar a cabo esta atribución. Ver XıL Rios, J. A., y otros, op. cit., pág. 53. 
magistratura española no hay un juez ni un magistrado... que se deje cohechar; pero creo que las cuatro quintas partes son débiles ante los halagos, los temores o las amenazas de politiquismo ${ }^{62}$. La atribución al Consejo de la potestad reglamentaria externa en este ámbito es una garantía esencial para lograr la efectiva independencia jurídica.

g) Por último, hay que señalar una competencia establecida en la vigente ley y que se cifra en atribuir al Consejo la publicación oficial de la colección de jurisprudencia del Tribunal Supremo, que hasta ahora habían asumido determinadas editoriales privadas.

\section{Responsabilidad del Consejo}

La Constitución no considera al Consejo General del Poder Judicial responsable políticamente; es el Gobierno quien responde de la eficacia de la justicia como un ámbito esencial en la dirección de la política interior que le compete. La responsabilidad política conlleva el cese inmediato del inculpado, lo que no concuerda con la inamovilidad que se predica de los miembros del Consejo y la duración concreta de su mandato.

Ahora bien, el Consejo ha de dar cuenta de su labor a las Cortes Generales; "elevará" ${ }^{63}$, dice la Ley Orgánica de 1985, anualmente a las Cortes Generales una Memoria. La Ley Orgánica de 1980 exigía que se remitiese «a las Cortes Generales y al Gobierno una Memoria anual sobre el estado y las actividades de la Administración de Justicia" (art. 4).

La Ley Orgánica de 1985, en su artículo 109, concreta el contenido de la misma, siguiendo el enfoque dado en la práctica por el primer Consejo, estableciendo tres apartados de información:

- Estado, funcionamiento y actividades del propio Consejo.

62 Citado en nota 12.

63 Término discutido y considerado en algunos sectores como muestra clara del papel secundario del Consejo tras la Ley Orgánica de 1985. SálNz DE RoBLES, F.: "Poder Judicial y Consejo General del Poder Judicial», en Estudios sobre la Constitución Española, Homenaje al profesor E. García de Enterría, tomo IV, Civitas, Madrid, 1991, pág. 3006. 
- Estado, funcionamiento y actividades de los juzgados y tribunales.

- Necesidades que existen en materia de personal, instalaciones y recursos para el correcto desempeño de las funciones asignadas al Poder Judicial.

La elaboración de esta Memoria es obligatoria para el Consejo - "elevará"- y su destinatario serán las Cortes Generales; su debate posterior es potestativo para las Cámaras — "podrán debatir»-; la ley, sin embargo, establece un procedimiento de discusión, comparecencias, posibles mociones y preguntas de obligada contestación por parte del Consejo; con ello, el Parlamento recibe una información directa sobre el funcionamiento y necesidades de la justicia y sobre la labor llevada a cabo por su órgano de gobierno; la práctica parlamentaria ha asumido la realización de este debate desde la segunda Memoria presentada por el Consejo. Al margen de la Memoria, el Gobierno recibirá anualmente una relación circunstanciada de las necesidades que estime existentes, a través del Ministerio de Justicia (art. 37.2 LOPJ).

La responsabilidad que pueda generar esta Memoria se podría desglosar de la siguiente forma:

En primer lugar, sólo es posible señalar una responsabilidad política del Gobierno en cuanto a que no haya proporcionado a la Administración de Justicia y al propio Consejo los medios exigidos para su adecuado funcionamiento y no haya atendido las peticiones de envío a la Cámara de aquellos proyectos de ley esenciales para que el ciudadano logre una tutela efectiva de los jueces y tribunales; todo ello englobado en la dirección gubernamental de la política interior, de la que es responsable ante el Parlamento.

En segundo lugar, podría aludirse a una responsabilidad del Parlamento ante el cuerpo electoral respecto al Consejo elegido por él, que se verá como una actuación más de la mayoría y la oposición en las próximas elecciones.

Por último, la información pública realizada por el Consejo ante las Cámaras puede y debe incidir en ese control difuso ejercido por la opinión pública, generador de unos criterios que se aplicarán en las urnas.

Es, por tanto, una responsabilidad política indirecta que en ningún momento recae sobre el Consejo desde el momento en que sus competencias, reducidas al mínimo constitucional, no deciden la política judi- 
cial, diseñada por el Gobierno ${ }^{64}$; pero ambas instancias, Ejecutivo y Legislativo, deben atender las demandas presentadas por el Consejo y adecuar a ellas sus decisiones políticas, el presupuesto y las normas legislativas, en una coordinación esencial entre los poderes del Estado; en este sentido, la Memoria puede y debe ser un eficaz instrumento de uinformación, comunicación y coordinación" entre Consejo y Cortes ${ }^{65}$.

\section{Estatuto jurídico de los Vocales del Consejo}

El Tribunal Constitucional sitúa la eficacia del Consejo respecto a la defensa de la independencia judicial en que ocupe una posición autónoma y no subordinada a los demás poderes públicos y no en que sea el órgano de autogobierno de los jueces ${ }^{66}$. Por tanto, es fundamental conocer el estatuto jurídico de los miembros del Consejo General del Poder Judicial y valorar si está garantizada esa autonomia que impida la dependencia de aquéllos respecto a otras instancias de poder; en este punto, la regulación actual es muy parecida a la establecida en la Ley Orgánica de 1980.

La situación otorgada por el ordenamiento jurídico a los miembros del Consejo, siguiendo de forma resumida al profesor Gerpe Landín, es la siguiente ${ }^{67}$ :

a) Exigencia de mayoría cualificada para las propuestas parlamentarias; aunque la elección de los Vocales del Consejo se abordará más adelante, se puede adelantar la exigencia constitucional de una mayoría cualificada de $3 / 5$ que obliga a lograr un consenso entre los grupos parlamentarios; ello supone la necesidad de participación de la oposición en el acuerdo y, en consecuencia, evita la dependencia absoluta de un solo partido. Esta mayoría tan amplia exige unas negociaciones dificultosas con el riesgo de no llegar a un fácil acuerdo y paralizar el órgano; la ley

64 Gerpe Landin, en este sentido, considera que sólo en el supuesto de que el Consejo tuviera una competencia de dirección de la política judicial diseñada legislativamente por las Cortes, podía ser la Memoria un instrumento de exigencia de responsabilidad política: "La composición del Consejo General del Poder Judicial", en $R C E C$, n..9 9, pág. 166.

${ }_{65}$ GerPe Landín, op. cit., loc. cit.

66 STC 108/86 de 29 de julio, F.J. 10.

67 Op. cit., págs. 169-174. Ver en estas páginas el iter parlamentario de cada precepto. Véase Terol BeCerra, M. J., op. cit., págs. 89-94. 
trata de evitar esta situación exigiendo al Presidente que seis meses antes de la expiración del mandato inste a las Cámaras para que procedan a la elección de los nuevos Vocales. Dada la dificultad en lograr una ma: yoría tan amplia para proponer la elección, el Consejo saliente continua: rá en funciones hasta la toma de posesión del nuevo Consejo (art. 115-1 y 2); pese a ello, la forzada situación de interinidad no cabe duda que debilita la institución.

b) La Constitución exige una profesionalización de los componentes - juristas de diferentes ámbitos-que dé una visión objetiva de la Administración de Justicia y evite el tan temido corporativismo. Al mismo tiempo crea un amplio cuerpo de juristas que actuará con métodos jurídicos y no políticos ${ }^{68}$.

c) El artículo 122 de la Constitución establece un mandato de cinco años, que no coincide con el de las Cámaras y evita el considerar al Consejo como un simple comisionado de las mismas.

d) El artículo 119 LOPJ establece que los Vocales del Consejo "no estarán ligados por mandato imperativo alguno y no podrán ser removidos de sus cargos sino por agotamiento de su mandato, renuncia, incapacidad, incompatibilidades o incumplimiento grave de los deberes del cargo..."; esta prohibición incide en la independencia que han de tener los Vocales para ejercer sus funciones, al margen de sus electores, que no podrán revocarles ni influir en sus decisiones. Esta garantía es perfeccionada con la prohibición de reelección inmediata de los salientes y de elección de quienes presten servicios en los órganos técnicos del Consejo (art. 112.4). Ambas exigencias refuerzan la independencia de los Vocales, evitando una hipotética docilidad ante la posibilidad de permanencia en el cargo.

e) Los Vocales del Consejo —dice el art. 120 LOPJ_ «no podrán ser promovidos durante la duración de su mandato a la categoría de magistrados del Tribunal Supremo, ni nombrados para cualquier cargo de la carrera judicial de libre designación o en cuya provisión concurra apreciación de méritos"; es decir, salvo el normal ascenso dentro del escalafón, la ley evita que las facultades de libre designación que tiene el Consejo sean utilizadas en la promoción de sus propios Vocales. Todo ello incide en la autonomía de que ha de gozar el órgano para poder garantizar la independencia del Poder Judicial.

${ }_{68}$ Ver XIOL Ríos, J. A., y otros, op. cit., págs. 25-39. Ver STC 108/1986, de 29 de julio, F.J. 13. 
f) La ley establece un amplio régimen de incompatibilidades que obligan al miembro del Consejo a dedicarse exclusivamente a su función, al abrigo de cualquier tipo de influencias o presiones; no podrán ocupar otro puesto, profesión o actividad, públicos o privados, por cuenta propia o ajena, retribuidos o no, a excepción de la mera administración del patrimonio personal o familiar; además, les serán aplicables las incompatibilidades específicas de los jueces y magistrados (arts. 117 y 389.2 LOPJ). Como consecuencia de la dedicación absoluta exigida expresamente por la ley, los miembros del Consejo percibirán, durante su mandato, una retribución única y exclusiva, "en atención a la importancia de su mandaton (art. 121), y, por lo tanto, suficiente.

Todas estas garantías que la ley establece en torno a los Vocales del Consejo hacen razonable el considerar que ocupan una posición juridica autónoma que les permite decidir con objetividad sobre aquello que afecta al estatuto de jueces y magistrados. Pese a ello, la perniciosa práctica política desarrollada en la elección parlamentaria, iniciada tras la entrada en vigor de la actual Ley Orgánica, ha influido en la opinión pública generando un clima de desconfianza hacia el órgano, como se verá al examinar este aspecto ${ }^{69}$.

69 De forma muy resumida, ya que su estudio no es objeto de atención en este momento, el Consejo General del Poder Judicial se articula en los siguientes órganos (art. 122 LOPJ):

1. Presidente del Consejo y del Tribunal Supremo, nombrado por el Rey a propuesta del Consejo por mayoría de 3/5; podrá ser reelegido una vez y ha de pertenecer a las mismas categorías profesionales que los Vocales. Ostenta la representación del Consejo General del Poder Judicial (arts. 123 y 125 LOPJ).

2. Vicepresidente: propuesto por el Pleno entre sus Vocales, por mayoría de $3 / 5$ y nombrado por el Rey. Sustituye al Presidente en caso de vacante, ausencia, enfermedad u otro mtivo legítimo (arts. 123 y 124 LOPJ).

3. Pleno: válidamente constituido con la presencia mínima de catorce Vocales (art. 127 LOPJ). Ejerce las funciones más importantes atribuidas al Consejo.

4. Comisión Permanente: formada por el Presidente y cuatro Vocales, dos pertenecientes a la carrera judicial y dos ajenos a ella. Prepara las sesiones del Pleno y vela por el cumplimiento de sus acuerdos (arts. 130 y 131 LOPJ).

5. Comisión disciplinaria: integrada por cinco miembros, tres de la carrera judicial y dos ajenos a ella. Le compete la instrucción de expedientes e imposición de sanciones a jueces y magistrados (arts. 132-133 LOPJ).

6. Comisión de calificación: formada por cinco miembros, tres pertenecientes a la carrera judicial y dos ajenos a ella. Le compete informar sobre los nombramientos efectuados por el Pleno (arts. 134, 135 y 136 LOPJ).

Los acuerdos de los órganos colegiados del Consejo serán adoptados por mayoría de los miembros presentes; quien presida tendrá voto de calidad en caso de empate. Las deliberaciones tendrán carácter reservado y el Vocal que disintiera podrá formular voto particular (art. 137 LOPJ). 


\section{D) ELECCIÓN DE LOS VOCALES DEL C.G.P.J.}

Ha sido y sigue siendo uno de los puntos que ha desatado mayor polémica en la doctrina y en los medios de comunicación. El artículo 122.3 de la Constitución dice:

«El Consejo General del Poder Judicial estará integrado por el Presidente del Tribunal Supremo, que lo presidirá, y por 20 miembros nombrádos por el Rey por un período de 5 años. De éstos, 12 entre jueces y mạgistrados de todas las categorías judiciales, en los términos que establezca la Ley Orgánica; 4 a propuesta del Congreso de los Diputadós y 4 a propuesta del Senado, elegidos en ambos casos por mayoría de $3 / 5$ de sus miembros entre abogados y otros juristas, todos ellos de reconocida competencia y con más de 15 años de ejercicio de su profesión".

Quien se asoma por vez primera a esta norma entiende que hay un mínimo de 8 Vocales, juristas de reconocida competencia, que han de ser elegidos por las Cámaras; junto a ellos, 12 Vocales, de obligada procedencia judicial, serán elegidos conforme determine una futura ley orgánica.

Sin entrar en la tramitación constitucional del precepto, muy estudiada ${ }^{70}$, de forma resumida se puede decir que si bien el anteproyecto de Constitución expresaba claramente que «doce de los miembros del Consejo serán nombrados a propuesta en representación de las distintas categorías judiciales", la Ponencia varió la redacción, en el sentido de que 10 Vocales serían propuestos entre jueces y magistrados en los términos que estableciera la ley orgánica y los 5 restantes por el Congreso de los Diputados; posteriormente se modificará, en Comisión, el número de Vocales -20-, siendo propuestos 12 entre jueces y magistrados, 4 por el Congreso y 4 por el Senado. Pese a que la idea general continuó siendo la elección por y entre los jueces y magistrados, no hubo una decisión final mayoritaria que originase su inclusión en la redacción, sino que se dejó a la ley orgánica posterior el regular el procedimiento de elección ${ }^{71}$.

Las resoluciones definitivas de la Comisión Permanente y de la Comisión disciplinaria serán impugnables en alzada ante el Pleno del Consejo. Los actos, resoluciones y disposición emanados del Pleno serán recurribles en vía contencioso-administrativa ante la Sala correspondiente del Tribunal Supremo (art. 143 LOPJ).

70 Ver Cavero latalllade, I., op. cit., págs. 483-492, y Gerpe Landín, M., op. cit., págs. 145-157.

71 Ver lo expuesto por la STC 108/1986, de 29 de julio, F.J. 13, y, en concreto, Sesión de 8 de junio de 1978, Comisión de Constitución del Congreso de los Diputados: Constitución española. Trabajos parlamentarios, Servicio de Publicaciones de las Cortes Generales, Madrid, 1980. 
La Ley Orgánica del CGPJ de 1980 siguió el criterio que entonces dominaba en la Cámara y estableció en el artículo 12 que "los Vocales del Consejo General de procedencia judicial serán elegidos por todos los jueces y magistrados que se encuentren en servicio activo"; en los preceptos siguientes reguló el procedimiento electoral concreto.

El primer Consejo, elegido según lo previsto en la Ley Orgánica de 1980 , creó amplias expectativas de autonomía, se consideró titular de importantes competencias y llamado a desempeñar un relevante papel político. La Ley Orgánica del Poder Judicial de 1985 da un giro total y en el artículo 112 establece que "los Vocales del Consejo General del Poder Judicial serán propuestos por el Congreso de los Diputados y por el Senado". "Cada Cámara elegirá, por mayoría de $3 / 5$ de sus miembros, 4 Vocales entre abogados y otros juristas de reconocida competencia con más de 15 años en el ejercicio de su profesión». "Además, cada una de las Cámaras propondrá, igualmente por mayoría de $3 / 5$ de sus miembros, otros 6 Vocales elegidos entre jueces y magistrados de todas las categorías judiciales que se hallen en servicio activo".

Esta ley no sólo modifica el sistema de elección de los Vocales del Consejo, sino que corta tajantemente los visos de autonomía del órgano, le priva de competencias, cercena otras y solamente le atribuye una facultad nueva: la publicación de las Sentencias del Tribunal Supremo, que supone el acento final que remarca lo que es el Consejo General del Poder Judicial: un órgano instrumental, de relevancia constitucional, con funciones administrativas y consultivas ${ }^{72}$.

\section{Criterios expuestos por los Grupos Parlamentarios en la discusión del Proyecto de Ley}

El legislador ordinario de 1980 tuvo muy presente, a la hora de elaborar la Ley Orgánica del Consejo General del Poder Judicial, el sistema político italiano; de acuerdo con este esquema, valora especialmente el principio de autogobierno $y$, en consecuencia, otorga a los propios jueces y magistrados la elección de sus representantes en el Consejo, es-

72 Ver esquema propuesto por SÁINZ DE RoBLES sobre el reparto de competencias entre los poderes del Estado, en orden a la justicia, con posterioridad a la Ley Orgánica del Poder Judicial de 1985, op. cit., págs. 2998-2999. 
tructurando las diferentes sensibilidades judiciales a través de las tres asociaciones profesionales ${ }^{73}$.

El Gobierno socialista, en 1984, envía al Congreso de los Diputados un proyecto de ley orgánica ${ }^{74}$ que, si bien acorta las competencias que la regulación anterior había reconocido al Consejo y limita la idea de autogobierno generada por aquéllas, no modifica el sistema de elección de los Vocales, sino que mantiene que los procedentes de la carrera judicial serían elegidos "entre" y "por» todos los jueces y magistrados en servicio activo, pretendiendo modificar solamente la forma de escrutinio mayoritaria. Será en la Comisión de Justicia del Congreso de los Diputados de 6 de marzo de $1985^{75}$ donde los Grupos parlamentarios socialista y vasco (PNV) apoyan la Enmienda 25 firmada por el Diputado de Euskadiko Ezquerra Juan M.ª Bandrés, redactada en los siguientes términos: "Los Vocales serán nombrados, 1 a propuesta dèl Congreso, 10 a propuesta del Senado, por mayoría de $3 / 5$ de sus miembros entre jueces y magistrados de todas las categorías judiciales y entre abogados y otros juristas...", y justificada en hacer más efectivo el principio del artículo 117.1 de la Constitución, que señala que "la justicia emana del pueblo..." ${ }^{76}$; sin embargo, el Diputado vasco pretendía unir esta legitimación parlamentaria directa a unas amplias competencias del Consejo, con posibilidad, incluso, de responsabilidad políticạ; opción desechada por el Grupo Socialista, que ve en la Enmienda Bandrés el acento final a la devaluación, pretendida en su proyecto, del ór-

73 En igual sentido, Xıol Ríos, J. A., y otros, op. cit., págs. 38 y ss.

74 B.O.C.G., n. 118-1, serie A, de 19-IX-1984.

75 Ley Orgánica del Poder Judicial 6/1985, de 1 de julio: Trabajos parlamentarios, Cortes Generales, Madrid, 1986, tomo II, pág. 908.

Todo el iter legislativo es desarrollado por CaVero Lataillade, l., en op. cit., págs. 535 y ss. Por su parte, Gerpe Landín, en op. cit., págs. 155 y ss., ordena las Enmiendas presentadas al Proyecto del Gobierno de la siguiente manera:

Primer bloque: mantienen la elección judicial y la fórmula electoral y disienten en la composición de las listas, proponiendo que estén formadas por jueces y magistrados sin fijar puestos por categorias:

Grupo Comunista (Enmienda 856).

Grupo Vasco (PNV) (Enmienda 21).

Grupo Socialista (Enmienda 691).

Segundo bloque: mantienen la elección judicial y fijan la composición de las listas, aunque optando por la lista abierta (2 magistrados del Tribunal Supremo, 6 magistrados y 4 jueces):

Minoría Catalana (Enmienda 462).

Grupo Popular (Enmiendas 1004 y 1005).

Tercer bloque: la Enmienda n. 25 del Diputado Bandrés, que atribuye al Parlamento la total elección de los Vocales del Consejo.

${ }^{76}$ Pág. 193 de los trabajos parlamentarios citados. 
gano de gobierno del Poder Judicial ${ }^{77}$. En la discusión parlamentaria es preciso poner de relieve, en primer lugar, los argumentos empleados a favor y en contra del espíritu del proyecto de Ley y, en segundo lugar, de la modificación en el procedimiento de elección de los Vocales; argumentos que se van a repetir en Comisión, en el Pleno del Congreso y posteriormente en el Senado.

a) Los argumentos utilizados por los grupos parlamentarios sobre el nuevo Proyecto de Ley se pueden resumir de la siguiente forma:

El Grupo Parlamentario Socialista parte de que el modelo de autogobierno pretendido no se explicita en la Ley Orgánica de 1980, sino que se debe a interpretaciones posteriores, no existe en ningún país y no se corresponde con un órgano irresponsable políticamente que no puede ser censurado ni obligado a dimitir. Ha de ser el Gobierno, responsable ante el Parlamento, quien asuma las competencias relativas al servicio público de la justicia ${ }^{78}$.

A la contra, y desde el Grupo Parlamentario Popular fundamentalmente, se achaca al Ejecutivo una constante desconfianza hacia el órgano de gobierno y un cambio de criterio radical del Sr. Ledesma como Vocal del Consejo en 1980 y como Ministro de Justicia que presenta el Proyecto de Ley en 1985, haciendo tabla rasa de todos sus criterios jurídicos anteriores ante la presión de los criterios políticos ${ }^{79}$.

En una valoración de estos criterios, entiendo que, efectivamente, el Gobierno no puede renunciar a dirigir una parcela tan importante de la política interior como es la Administración de Justicia; en segundo lugar, la dirección política, en un sistema parlamentario, corresponde al órgano procedente del Parlamento y responsable ante él. Por último, la existencia de un órgano específico de gobierno del Poder Judicial tiene como única y exclusiva justificación el aislar el ámbito profesional del juez de las influencias $y$ directrices del Ejecutivo, a fin de salvaguardar su independencia jurídica.

77 El propio Diputado de E.E., años después, explica su auténtica intención en la prensa y asume su parte de responsabilidad en las polémicas elecciones de los Vocales del Consejo en su 1. enovación parlamentaria: "Yo tuve la culpa", EI País, 31-X-1990.

78 Sres. Sotillos y Sáenz Cosculluela, págs. 7393 (13 de noviembre de 1984) y 8590 ( 6 de marzo de 1985) del Diarios de Sesiones del Congreso, números 164 y 274 , en Trabajos parlamentarios, cit., págs. 105 y ss. y 930 y ss.

79 Sr. AlzAGA, pág. 7382 (13 de noviembre de 1984) del Diario de Sesiones del Congreso, n. 9164 , en Trabajos parlamentarios, cit., págs. 105 y ss. 
Respecto a los argumentos de oportunidad política expuestos por el Grupo Parlamentario Popular, es cierto que existió y existe un fuerte recelo del Ejecutivo hacia el Judicial, recelo que se ve aumentado durante el mandato del Primer Consejo, dado el concepto que tuvo de sus competencias y autonomía. La defensa socialista de tal ámbito en 1980 se puede situar junto a otras defensas tácticas hechas como oposición y drásticamente modificadas en el momento en que accedió a la responsabilidad de Gobierno, con una abultada mayoría que le permitió lograr amplias cotas de poder, lo que hizo con eficacia y arrogancia.

b) Los argumentos de los grupos parlamentarios sobre la nueva procedencia de los miembros del Consejo General del Poder Judicial se pueden dividir en los siguientes bloques:

En contra de la elección parlamentaria:

- El Grupo Parlamentario Centrista entiende que este sistema no garantiza el que accedan los más idóneos; vincula la elección al Legislativo y lo hace afín al Ejecutivo, menoscabando la independencia judicial ${ }^{80}$.

- El Grupo Parlamentario Minoría Catalana considera que la regulación anterior sobre el procedimiento de elección establecía un sistema compensatorio; con el que se quiere implantar se menoscaba el control judicial del Ejecutivo ${ }^{81}$.

- El Grupo Parlamentario Popular define al Consejo procedente de las Cortes como un comisionado de las mismas, igual que el Tribunal de Cuentas y el Defensor del Pueblo, pudiendo llegarse al control del Consejo por parte del Ejecutivo ${ }^{82}$.

Estos criterios ponen de relieve, como luego lo hará el Tribunal Constitucional, el peligro cierto de que los grupos parlamentarios enfoquen la elección como el logro político de cotas de poder en el Consejo, convirtiendo al órgano de gobierno en una minicámara con todas las tensiones políticas propias de ésta. De todas formas, si el Consejo es simplemente el órgano administrativo que decide exclusivamente sobre el

80 Sr. NúÑez Pérez, págs. 8586 y 8588 (6 de marzo de 1985) del Diario de Sesiones del Congreso, n. 274, en Trabajos parlamentarios, cit., págs. 918 y ss.

${ }_{81}$ Sr. TRíAS DE BES, pág. 8588 (6 de marzo de 1985) del Diario de Sesiones del Congreso, n. 274, en Trabajos parlamentarios, cit., págs. 921 y ss.

${ }_{82}$ Sr. Ruiz Gallardón, pág. 8580 (6 de marzo de 1985) del Diario de Sesiones del Congreso, n.ㅇ 274, en Trabajos parlamentarios, cit., págs. 913 y ss. 
estatuto jurídico de los jueces, el riesgo es menor; si el Consejo participa en la política judicial, como fueron sus pretensiones, el riesgo podría llegar a ser alarmante, volviéndose a confundir con el tradicional Ministerio de Justicia.

\section{A favor de la elección parlamentaria:}

(El Grupo Parlamentario Socialista se manifiesta en igual línea argumental que la señalada a continuación)

- El Diputado Bandrés defiende su enmienda con los siguientes criterios: en primer lugar, la Constitución exige que un mínimo de 8 Vocales sean elegidos por el Parlamento y que los 12 restantes lo sean entre jueces y magistrados, dejando este procedimiento concreto a la decisión de la futura ley orgánica, al no haberse llegado a un acuerdo sobre aquél, con independencia de lo que se pensase en aquel momento. En segundo lugar, si la justicia emana del pueblo es éste quien ha de nombrar a los que tengan que velar por la independencia del Poder Judicial, otorgándoles legitimidad. En tercer lugar, la Constitución no pretendió hacer de la judicatura un Estado dentro del Estado, sin vinculación con otro poder, sino sólo pretendió garantizar la independencia de aquélla. Por último, la justicia ya está politizada puesto que los jueces tienen una ídeología concreta; legitima más la elección parlamentaria que la corporativa ${ }^{83}$.

- El Grupo Parlamentario Vasco (PNV) resalta el que las asociaciones profesionales de los jueces son partidos dentro de la judicatura, lográndose un consenso más amplio a través de la elección parlamentaria; manifiesta su extrañeza de que se valore más el procedimiento de cooptación entre 2.086 magistrados que la elección por los representantes del cuerpo electoral del que emana la soberanía. En segundo lugar, los jueces son políticamente irresponsables, pues la memoria que han de presentar a las Cámaras sólo es un informe y una relación de necesidades; el Parlamento es, sin embargo, responsable ante el cuerpo electoral y de éste recibe un mandato directo ${ }^{84}$.

83 Págs. 8574 y ss. (6 de marzo de 1985) del Diario de Sesiones del Congreso, n. 274, en Trabajos parlamentarios, cit., págs. 908 y ss.

84 Sr. Vizcaya Retama, pág. 8578 (6 de marzo de 1985) del Diario de Sesiones del Congreso, n. 274, en Trabajos parlamentarios, cit., pág. 912. 
En toda la discusión parlamentaria subyace, a mi modo de ver, un confusionismo entre los conceptos de legitimidad e independencia del Poder Judicial y autonomía de su órgano de gobierno.

La legitimidad del Poder Judicial, legitimidad de ejercicio al estar sọmetido únicamente al ordenamiento jurídico que procede del órgano representativo, nada tiene que ver con la forma de elección del Consejo General del Poder Judicial, que es un órgano de garantía de aquella independencia; para que ésta sea efectiva se exige -lo exige la experiencia histórica- que la instancia que decide sobre la carrera profesional dèl juez, sea ajena al Gobierno ${ }^{85}$ y tenga la suficiente autonomía para no estàr supeditado a éste; esta autonomía ha de lograrse mediante la exigencia legal de determinadas condiciones para el ejercicio de sus competencias por parte de los Vocales del Consejo: la prohibición de mandato imperativo, plazo concreto de ejercicio, rígidas incompatibilidades, prohibición de reelección y retribución suficiente, entre otras ${ }^{86}$. Si estas cautelas no son suficientes, es la práctica política la perniciosa ${ }^{87}$, pues los tentáculos de los partidos políticos llegan de igual forma a los grupos parlamentarios que a las asociaciones profesionales de la judicatura. Los Consejos posteriores a la Ley Orgánica del Poder Judicial se ven devaluados y sometidos por el recorte drástico de competencias que no le correspondían, la cicatería de la ley en otras facultades que podría tener $y$ el papel preponderante del $\mathrm{Mi}$ nisterio de Justicia, en mucha mayor medida que por el procedimiento de elección, con independencia de que el Parlamento sea un órgano político que siempre actuará con criterios políticos, como se verá más adelante.

\section{Causas de la modificación introducida en la LOPJ de 1985}

La regulación del Consejo General del Poder Judicial procedente de la Ley Orgánica vigente ha sido muy criticada, desde todas las ópticas,

${ }_{85}$ Ver STC 108/1986, de 29 de julio, F. J. 7.

86 Sent. cit., F. J. 10.

${ }_{87}$ A esa práctica perniciosa se refiere el Tribunal Constitucional en la Sent. 108/1986, de 29 de julio, cuando dice que "si las Cámaras, a la hora de efectuar sus propuestas olvidan el objetivo perseguido $y$, actuando con criterios admisibles en otros terrenos, pero no en éste, atienden sólo a la división de fuerzas existentes en su propio seno y distribuyen los puestos a cubrir entre los distintos partidos en proporción a la fuerza parlamentaria de éstos", y concluye que en el caso de que sucediera lo anunciado (que ya había sucedido, pues la Sentencia es posterior a la elección del segundo Consejo) "convendría su sustitución", pese a que el precepto no es inconstitucional. F. J. 13, Sent. cit. 
y calificada de "movimiento sísmico" ${ }^{88}$, de "mutación regresiva de la norma fundamental» ${ }^{89}$, de "ánimo depurador de la magistratura» ${ }^{90}$, de "giro copernicano" " ${ }^{91}$, etc.

El proyecto de ley del Gobierno devaluaba ciertamente las competencias atribuidas al órgano con anterioridad, aumentando considerablemente las correspondientes al Ministerio de Justicia, pero no incidia en su composición hasta que en la tramitación parlamentaria es aceptada parte de la enmienda Bandrés, "acogida con verdadero entusiasmo por el Grupo Socialista del Congreso" ${ }^{92}$. Ello responde a varias razones, que podrian resumirse de la siguiente manera:

a) Existe una inicial desconfianza por parte del resto de los poderes del Estado hacia una organización judicial que cuenta con la presencia de una mayoría conservadora procedente del franquismo y que integra un poder del Estado carente de legitimación democrática ${ }^{93}$.

b) Existe una situación cada vez más tensa entre el Gobierno ${ }^{94}$ y el Consejo, debido a su pretendida actuación como órgano activo, interesado en participar en la política judicial del Gobierno de forma muy directa ${ }^{95}$, con una interpretación de sus competencias muy alejada de la realidad legal y entendidas como un autogobierno del Poder Judicial de amplio contenido ${ }^{96}$, reivindica como esencial a esa función de gobierno la potestad reglamentaria externa, la gestión del presupuesto de la Administración de Justicia, la iniciativa legislativa, la totalidad de las competencias funcionales sobre el personal auxiliar y colaborador de la Ad-

86 Cavero lataillade, I., op. cit., pág. 496.

89 J. DE Esteban, «Las tribulaciones del Poder Judicial», en El Mundo, 2-X-1991.

90 SáINZ DE Robles, F. C.: "La parlamentarización del Poder Judicial», op. cit., pág. 206.

XıL Rlos, J. A., Y otros, op. cit., pág. 38.

SAINZ DE Robles, F. C., op. cit., loc. cit.

93 SÁInz de Robles, F. C.: «Poder Judicial y Consejo General del Poder Judicial», en Estudios sobre la Constitución Española..., cit., pág. 3006.

${ }_{94}$ Ya el Gobierno de UCD se enfrentó al Consejo por el intento de este órgano de determinar la politica judicial; el profesor Gerpe cita cómo el Consejo de Ministros, por Acuerdo de 24-X-1982, presenta requerimiento de incompetencia al Consejo como trámite previo de un conflicto entre órganos constitucionales; el conflicto está en trámite cuando el Gobierno de UCD es sustituido por el primer Gobierno socialista, quien revoca el Acuerdo. Op. cit., pág. 154.

95 "Motor de una política judicial del Estado», dice SÁINZ DE Robles en "La parlamentarización...», cit., pág. 206.

96 El Consejo como un poder autónomo "vértice de un poder independienten: Gerpe Landín, M., op. cit., pág. 152. 
ministración de Justicia e, incluso, el refrendo por parte de su Presidente de los actos del Rey, con lo que ello supone de responsabilidad política directa ${ }^{97}$. La primera manifestación institucional del Consejo se refiere expresamente a su intención de "ocupar todo el espacio político que como gobierno de un poder del Estado debía corresponderle ${ }^{98}$.

c) Existe un estricto motivo de reparto de poder, generado por la propia composición del primer Consejo. Pese a que este órgano fue recibido con reticencia por la derecha judicial y creado con el apoyo de los partidos democráticos progresistas ${ }^{99}$, tras la primera elección las doce Vocalías de procedencia judicial serán copadas por la conservadora "Asociación profesional de la Magistratura ${ }^{100}$; ello unido a los Vocales procedentes de la derecha de las Cámaras da una ideología predominante en el órgano ${ }^{101}$ imposible de modificar con este sistema de elección, mientras que la elección de todos los Vocales a través del Parlamento, con una mayoría socialista, posibilita el acceso al Consejo de los progresistas $^{102}$.

Éste ha sido, en mi opinión, el definitivo motor del cambio, en contra de todas las manifestaciones hechas por el Gobierno y su Ministro de Justicia durante la etapa de oposición parlamentaria.

d) Finalmente, el poco interés manifestado en las primeras Memorias del Consejo por sancionar el incumplimiento y la corrupción de algunos sectores judiciales, van a generar un ambiente parlamentario de acusaciones de corporativismo, como consecuencia de la forma de elección, en contra del interés general por la moralización pública ${ }^{103}$; éste va a ser el argumento fundamental esgrimido contra la interpretación vi-

97 Ver XIOL Rios, J. A., y otros, op. cit., pág. 59; ello es postulado a través dè los informes a los proyectos de Ley Orgánica del Poder Judicial; supone "una concepción sumamente ambiciosa de autogobierno, queriendo llevar la autonomía de la organización judicial a limites muy notables y alcanzar el techo constitucionaln.

pág. 17.

${ }_{98}$ Cit. por P. Andrés IBáñez en Justicia y conflicto, Tecnos, Madrid, 1986,

99 Órgano concebido por «justicia democrática» en las postrimerías del franquismo. Ver El Pais, editorial de 26-IX-1991.

100 P. ANDRÉs lBÁÑEZ se refiere a las incidencias de esta elección en Justicia y conflicto, cit., págs. 23 y ss.

101 Su Presidente será F. C. Sáinz de Robles y Rodríguez.

102 El progresista Álvarez CRUZ, E., lo dice claramente: «Algunas consideraciones sobre la posición constitucional del Poder Judicial", en El Poder Judicial, DGCE, Madrid, 1983, pág. 516.

${ }_{103}$ Ver AndRés lbáñez, P., op. cit., pág. 44. En igual sentido, Gerpe Landín recoge las críticas de Sáenz Cosculluela, Granados Calero y Sotillo Martí, del Grupo Parlamentario Socialista, sobre "la falta de atención a la corrupción, los horarios y el mal funcionamiento de la Escuela Judicial...». Op. cit., pág. 154 y nota 37. 
gente entonces sobre la designación de los Vocales de procedencia judicial "por" y "entre" jueces y magistrados en activo.

\section{Desarrollo de las elecciones del 2.. y 3. CGPJ: repercusiones en la opinión pública}

El 23 de octubre de 1985 finaliza el mandato del primer CGPJ y se produce la renovación de acuerdo con la nueva regulación, recurrida ante el Tribunal Constitucional ${ }^{104}$.

El Grupo Parlamentario Socialista, con una abultada mayoría y el apoyo de las Minorías Vasca y Catalana, logra el consenso exigido en la norma y ofrece un pacto a Alianza Popular que, lejos de sus iniciales posiciones de enfrentamiento y rechazo a participar, lo acepta; quedan excluidos el resto de los Grupos Parlamentarios ${ }^{105}$.

Se presenta una única lista, tanto en el Congreso, apoyada por los Grupos Parlamentarios Socialista, Minoría Catalana y Vasca y Popular, como en el Senado, apoyada por todos los Grupos Parlamentarios excepto el Mixto ${ }^{106}$. Gerpe Landín critica la nueva interpretación del artículo 122.3 de la Constitución, ya que no se respeta el número de 12 miembros de la carrera judicial puesto que se proponen 14 Vocales de este ámbito, rompiendo el equilibrio profesional establecido en la Constitución; respecto a la categoría de juristas, "dudamos - dice- que sea cobijo pacífico de miembros de la carrera fiscal, de juristas parlamentarios o de juristas di-

104 Esta primera renovación es estudiada por GeRPE LANDín en op. cit., págs. 161 y ss., a quien me remito, exponiendo resumidamente algunos datos que aporta.

${ }_{105}$ Grupo Mixto, Grupo Parlamentario Demócrata Popular y Grupo Parlamentario Centrista.

106 Congreso:

Vocales procedentes de la carrera judicial: A. Albasanz, P. García Manzano, J. A. Linares Lorente, M. Peris, C. Rodríguez Aguilera y J. Augusto de Vega.

Vocales juristas de reconocida competencia: P. Beltrán de Heredia, P. Castellanos, A. González Cuéllar, I. de Otto.

Senado:

Vocales procedentes de la carrera judicial: F. Fuet, E. Berlanga, A. del Cacho, J. Serrano, J. L. Calvo y V. de la Iglesia.

Vocales juristas de reconocida competencia: L. Vacas, A. Celaya, J. J. Martínez Zato y C. Alberdi.

Composición profesional: 14 jueces y magistrados, 2 fiscales, 2 catedráticos de Derecho, 2 abogados.

GeRPE LANDiN habla de que este Consejo está afectado de inconstitucionalidad (op. cit., pág. 170); esta violación del equilibrio aumenta el riesgo corporativo. 
rectores generales del Gobierno que los proponen; igualmente se obvian las formalidades exigidas hasta el punto que uno de los Vocales juristás de reconocida competencia no tiene los 15 años de ejercicio profesional exigidos ${ }^{107}$. De todo ello se hace eco la prensa, fustigando el interés político prioritario de los grupos parlamentarios, con claro olvido del daño irreparable que se hará al nuevo órgano, nacido con todos los recelos de la opinión pública ante su dependencia; incluso se hablará de quién va a ser el Presidente, mucho antes de que sea elegido efectivamente por el Consejo ${ }^{108}$.

El 23 de octubre finaliza el mandato del segundo Consejo, muy criticado por su ineficacia y sometimiento al Ejecutivo ${ }^{109}$. Pese a que tanto la renovación de 1985 como la de 1990 levantaron fuerte polémica en los medios jurídicos, de la que se hizo portavoz toda la prensa, voy a centrarme en esta última fecha, con acusaciones muy similares pero más cercana en el tiempo, menos estudiada y calificada desde todas las ópticas de "perversa» "110. Con motivo de esta elección, el Consejo se convertirá en el punto de mira de todos los analistas políticos, siendo criticado y fustigado el comienzo de su mandato, consecuencia de una negociación parlamentaria "descarnada y descarada" "1.

El Parlamento llega a un auténtico reparto de cuotas, en negociaciones a puerta cerrada entre los portavoces de los partidos mayoritarios y sus ejecutivas ${ }^{112}$, de la siguiente forma:

- 10 Vocales propuestos por el Grupo Parlamentario Socialista, más el futuro Presidente del Consejo ${ }^{113}$.

107 C. Alberdi.

108 Ver prensa de Madrid de los días 24 y 25 de octubre de 1985 sobre la elección de Antonio Hernández-Gil; este dato es interpretado como la supeditación del Consejo a la mayoría, que es quien decide — "a priori»- la presidencia dél mismo.

109 Ver, por ejemplo, Diario 16 de 23-X-1990.

110 Ver A. Garcia Martínez: «El Consejo General del Poder Judicial y la autonomía del Poder Judicial", en Publicaciones para el mundo del Derecho, Tapia, diciembre de 1990. Ver Diario 16 de 29-X-1990.

111 A. Garcia Martínez, op. cit., pág. 45.

112 T. González Ballesteros: «EI Parlamento y los jueces», El País, 22-X-90. Acusa a los grupos parlamentarios de no haber consultado ni a las Asociaciones de Jueces y Magistrados ni a los Colegios Profesionales; no hubo ningún tipo de dișcusión pública, sino una negociación secreta entre los portavoces de los partidos y sus ejecutivas.

${ }_{113}$ Presidente: P. Sala.

Vocales:

J. A. Xiol Ríos

E. Hernández Gutiérrez 
- 7 Vocales propuestos por el Grupo Parlamentario Popular, entre ellos el futuro Vicepresidente ${ }^{114}$.

- 1 Vocal propuesto por el Grupo Parlamentario de Centro Democrático y Social ${ }^{115}$.

- 1 Vocal propuesto por el Grupo Parlamentario de Minoría Catalana ${ }^{116}$.

1 Vocal propuesto por el Grupo Parlamentario Vasco ${ }^{117}$.

El Grupo Parlamentario Socialista rechaza las acusaciones manifestando que la candidatura elegida por el Parlamento representa a más del $90 \%$ de la Cámara y recoge las diferentes sensibilidades que política y judicialmente existen en el país ${ }^{118}$; enfrente, el Grupo Parlamentario de Izquierda Unida, que ha quedado fuera de las negociaciones, defiende el sistema de elección pero rechaza el procedimiento utilizado, criticando el que las fuerzas políticas "partidicen este órgano y sometan a disciplina de voto a sus comisarios" ${ }^{119}$. El Grupo Parlamentario Popular, a la inver-

M. T. Fernández de la Vega

S. Mestre Garcia

I. Sierra Gil de la Cuesta

T. Vives Antón

R. Fernández Montalvo

J. L. Granizo García-Cuenca

F. Jiménez-Lablanca Rubio

J. A. Belloch Julbe

(El País y Diario 16, 25-X-1990).

114 J. L. Manzanares (Vicepresidente), M. Mariscal de Gante Mirón, J. PadiIla Carballeda, J. A. Zarzalejos Altares, E. Gómez de Liaño, A. de la Oliva Santos, A. Marín Rico (El País y Diario 16, 25-X-1990)ç

115 J. J. Dávila LoRenzo (El País y Diario 16, 25-X-1990).

116 A. Bruguera Nante (EI País y Diario 16, 25-X-1990).

117 W. Diaz Argal (El País y Diario 16, 25-X-1990).

En esta ocasión, sin embargo, no se han oído críticas relativas al número de Vocales procedentes de cada ámbito profesional o la ausencia de requisitos formales en los candidatos; en este aspecto, el Parlamento - por no decir Ferraz y Génova- han sido más cuidadosos; ello demuestra que el control difuso que establece la opinión pública es eficaz.

Composición profesional de los Vocales:

- Jueces y magistrados: 12 ( 11 de la carrera, 1 del cuarto turno).

- Otros juristas: Fiscales, 2; Secretarios Judiciales, 1; Abogados, 2; Procuradores, 1; Catedráticos, 2

(EI País, 25-X-1990).

1tB Sr. Martín Toval, Diario 16, 25-X-1990.

119 P. Castellano, Diario 16, 9-XI-1990. 
sa, justifica los métodos empleados dentro de la normativa vigente, considerando que es ésta la que hay que modificar ${ }^{120}$.

Igualmente, las Asociaciones Profesionales de jueces y magistrados, con independencia de su ideología, coinciden en fustigar la forma en que se ha hecho la propuesta y las consecuencias de la misma en cuanto a la imagen dependiente del nuevo Consejo; la Asociación Profesional de la Magistratura, de corte conservador y mayoritaria en el primer órgano de gobierno, critica el sistema, solicitando que se elijan personas profesionalmente válidas y no cuotas, para lo que se precisaría una votación secreta y sin disciplina de partido; pide la vuelta al sistema mixto anterior ${ }^{122}$. A su vez, la asociación progresista Jueces para la Democracia califica al Consejo como "órgano tutelado" por la forma en que se ha llevado a cabo la propuesta y no por el sistema en sí; acusa al Grupo Parlamentario Socialista de la falta de atención a criterios de profesionalidad y a la ausencia de transparencia en los pactos, buscando prioritariamente personas que elijan a un Presidente nombrado por el Gobierno ${ }^{122}$. Por último, la asociación moderada Francisco de Vitoria acusa de partidista la decisión del Parlamento y pide se vuelva a la elección de los Vocales del Consejo por $y$ entre los jueces ${ }^{123}$.

La propuesta se formaliza el 6 de noviembre en el Congreso y el 12 del mismo mes en el Senado, ratificándose la lista publicada por toda la prensa el 25 de octubre anterior.

El nuevo Consejo, en su primera reunión el 7 de noviembre, elige al Presidente anunciado, pese a las presiones de la opinión pública pará que actuase con independencia de criterio ${ }^{124}$. El día 20 se elegirá al Vice-

120 Inicialmente se manifiestan dos criterios en este Grupo Parlamentario: el mantenido por 1 . Tocino, partidaria de no participar en las negociaciones, $y$ una segunda postura dominante, protagonizada por el portavoz Sr. Rato, que acepta las negociaciones al considerar que su Grupo no puede quedar fuera del Consejo (Diario $16,25-\mathrm{X}-1990$ ).

Posteriormente, tanto R. Rato como J. M.a Aznar, ante las críticas por los métodos empleados, manifiestan que han protestado los que se han quedado fuera del órgano (Diario 16, 30-X-1990 y 4-X|-1990).

121 Pradera, El País, 11-XI-1990, y Diario 16, 23-X-1990.

${ }^{122}$ Diario 16, 23-X-1990. Hay que tener en cuenta que el Grupo Parlamentario de Izquierda Unida no pudo participar en las negociaciones siendo un importante sector de la asociación Jueces para la Democracia.

$123 \quad A B C, 29-X-1990$. Posteriormente, en la Asamblea de la Asociación de Jueces Francisco de Vitoria, celebrada en Tenerife (EI Pais, 20-XI-1990 y 22-XI-1990):

${ }_{124}$ El 7 de noviembre se elige al propuesto $P$. Sala, a quien se acusa en là prensa de ser hombre de partido, muy cómodo para el Gobierno en su gestión al frente del Tribunal de Cuentas (EI Mundo, 2-XI-1990; EI País, 6-XI-1990). En la elec- 
presidente Manzanares, contrapartida del Grupo Parlamentario Popular por los votos dados a P. Sala ${ }^{125}$. Como anécdota curiosa y expresiva de todo el proceso, hay que aludir a la invitación recibida por los nuevos Consejeros para una reunión con los salientes, antes de celebrarse la elección en el Senado ${ }^{126}$.

Como se ha señalado, la propuesta parlamentaria del segundo Consejo ha sido calificada en los medios de comunicación como «espectáculo" ofrecido por los distintos grupos parlamentarios, resumiéndose las diferentes críticas en los siguientes puntos ${ }^{127}$ :

- No se ha valorado la cualificación profesional de los elegidos, sino su fidelidad al partido político.

- Decisión trasladada del ámbito parlamentario a la ejecutiva de los partidos políticos.

- Mercadeo de votos en función de los resultados electorales.

- Traslado de la lucha política a la justicia, buscando el control del CGPJ.

- Como conclusión, ausencia de debate público y alteración de los mecanismos de poder establecidos en la Constitución.

Como valoración de estos argumentos se puede señalar lo siguiente:

Los grupos parlamentarios partidarios del sistema actual basan su defensa en que no se puede admitir que un poder del Estado sea gobernado por dos mil y pico jueces, cuya actuación es acusada de cor-

ción se contabilizan 13 votos a P. Sala, 4 a S. Auger y 1 a J. Arozamena; ello se interpretó como una pequeña rebeldía de los Vocales, ya que se esperaban 17 votos a favor del primero. "...Todo, quizás hasta la disidencia controlada, estaba previsto" (El País, 9-XI-1990).

${ }^{125}$ El País, El Mundo y Diario 16 de 21-XI-1990.

126 El Mundo, 7-XI-1990.

127 "El laberinto del Poder Judicial", Bernat Freixes, J. M., El País, 17-XI1990; Diario 16, 22-X-1990; El País, 23-X-1990; Diario 16, 23-X-1990 y 8-XI-1990; EI Mundo, 4-XI-1990. J. Pradera, «Análisis político», El País, 11-XI-1990. 
porativista; los partidarios del sistema mixto de elección consideran que de esta forma se evita en mucha mayor medida la politización del órgano. Lo cierto es que los primeros serían minoritarios en el Consejo debido al dominio de la Asociación Profesional de la Magistratura, de tendencia conservadora; su única forma de controlar el Consejo radica en modificar el procedimiento de propuesta, dada la mayoría parlamentaria de la que disfrutan. A los segundos les sucede lo contrario: dominio del órgano con el sistema establecido en la Ley Orgánica de 1980 y supeditación al partido mayoritario con el sistema actual. En consecuencia, tanto un argumento como el otro ofrecen poca fiabilidad, $y$, desde luego, si en 1985 hubiera coincidido la mayoría judicial con la parlamentaria no se hubiese modificado el procedimiento, aunque sí, y esto es importante, las competencias excesivas que se atribuyó el primer Consejo. Ambos sistemas ofrecen riesgos evidentes, aunque, como señala el Tribunal Constitucional, es mayor el actual, pese a su corrección teórica ${ }^{128}$, debido a la práctica llevada a cabo por el Parlamento en lás dos elecciones realizadas hasta ahora ${ }^{129}$, conducidas por una mayoría sólida y arrogante, y que ha generado un estado de opinión crispad'o, que es el único que puede moderar con sus críticas la actuación de lós partidos y evitar esa desconfianza existente hacia toda institución procedente del Parlamento.

\section{E) ANÁLISIS DE LOS CRITERIOS MANIFESTADOS POR LOS DISTINTOS CONSEJOS EN SUS MEMORIAS}

Las Memorias elevadas por los distintos Consejos responden claramente al concepto que el órgano tiene de sí mismo, y éste es el aspecto a examinar, a través de la Introducción a los distintos informes ${ }^{130}$.

\footnotetext{
dente con la social.

${ }_{129}$ Igualmente que en las relativas al Tribunal de Cuentas y, en este momento, al Tribunal Constitucional. Negociaciones poco transparentes, con escasa o nula valoración de las cualidades profesionales, en las que el "do ut des" es el criterio dominante y en que sólo se irritan los perdedores.

130 Se han elegido tres Memorias concretas, una de cada mandato: 1982, 1990 y 1991, por las siguientes razones: En la primera, el Consejo analiza su actuación hasta ese momento y expone el papel político que cree que le corresponde y sus relaciones con los demás Poderes; la Memoria de 1990 se presenta ciomo balance del mandato del segundo Consejo; la última porque es la únića existente del órgano actual y en ella manifiesta sus criterios, marcando indirectamente las diferencias con el anterior. Publicadas por el CGPJ en las fechas correspondientes.
}

${ }^{128}$ Otorga al Consejo legitimidad democrática indirecta y mayoría coinci- 


\section{El primer Consejo General del Poder Judicial (1980-1985)}

El primer Consejo es optimista en sus previsiones de futuro, su papel político y su aceptación por la opinión pública ${ }^{131}$. Los criterios que inspiran esta línea de actuación son los siguientes:

a) Parte de la idea de que la política judicial no puede continuar siendo "un mero apéndice de la política interior que compete al Gobierno, sino algo distinton; pese a que la Ley Orgánica de 1980 atribuye al Ministerio el suministrar los medios que precisa la justicia (art. 6 L. 0.1/1980), "la exposición de cuáles son estos medios incumbe exclusivamente al Consejo General»" ${ }^{132}$. Es decir, el Consejo reivindica el diseño de la política judicial, a la que el Ejecutivo ha de aportar los medios materiales necesarios.

b) El Consejo se considera representante del Poder Judicial y entiende que le corresponde, en consecuencia, establecer las relaciones con el Poder Ejecutivo, en pie de igualdad entre ambos: "...Las relaciones entre el Poder Ejecutivo $y$ el Poder Judicial, y que no se traban entre el Gobierno, por una parte, $y$ jueces y magistrados, por otra, sino entre Gobierno y Consejo..., discurren... a un nivel desprovisto de cualquier supremacía entre ambos Poderes» ${ }^{133}$.

c) En las relaciones con el Parlamento, reconoce la superioridad de la representación popular $y$, en consecuencia, ante él se siente responsable de la política judicial, que considera le corresponde dirigir; ahora bien, dado el plazo fijo de su man-

131 Desde el inicio de su mandato, el Consejo elabora un informe muy completo sobre el funcionamiento de la Administración de Justicia, que figura como Anexo a la Memoria de 1982, confrontándolo con una encuesta encargada al CIS (Memoria de 1982, pág. 127), y que permite llegar a una doble evaluación: lo que verdaderamente hace la justicia y la imagen que presenta a los ciudadanos. El Consejo se expresa con optimismo en el siguiente sentido: "...El problema de la justicia ha hecho crisis... se conoce su etiología, se ha hecho el diagnóstico y puede iniciarse su tratamiento específico". (Memoria de 1982, pág. 15). Este optimismo durará hasta 1985; en la Memoria de este año, ya aprobada la LOPJ, el Consejo se limita a elaborar un enorme compendio de datos; el escepticismo impregna las cortas líneas de la Introducción.

132 Memoria de 1982, pág. 11. Ver, en este sentido, XıL Ríos, J. A. ,y otros, op. cit., pág. 49.

${ }_{133}$ Memoria, cit., pág. 19. Ver, en respuesta a este criterio, STC $47 / 1986$, de 17 de abril. 
dato establecido en la Constitución, "este tipo de responsabilidad se refleja, no en sanciones o en coerciones, sino en medios más difusos, morales, de tipo sociológico, como pueden ser la dación de cuenta, la censura y aun la mera queja o reproche y, en definitiva, la demostración de pérdida de confianza»" ${ }^{134}$.

d) El instrumento para establecer la relación entre Consejo y Parlamento es la Memoria, en la que se manifiestan las necesidades de la justicia, se proponen las soluciones y las demandas. El Consejo entiende que este documento deberá ser debatido en la Cámara, con la presencia del Presidente y los Vocales para aclarar y ampliar la información presentada y "deberá" ser respondido por aquélla; este acto tiene una doble vertiente: de colaboración entre Legislativo y Judicial y de control sobre el Consejo del "poder preeminente" ${ }^{135}$.

e) El Consejo, en su decisión de ocupar todo el espacio político que considera le corresponde como gobierno de un Poder dèl Estado ${ }^{136}$, interpreta de forma muy amplia determinadas competencias atribuidas legalmente.

e.1) Plantea la necesidad de que, bien la futura ley orgánica del Poder Judicial, bien el propio Tribunal Constitucional, establezcan un criterio sobre la facultad de iniciativa que le corresponde, dado que existen tesis contrapuestas sobre la misma ${ }^{137}$. En espera de la decisión, el Consejo opta por hacer uso de tal competencia, tanto en el

134 Memoria, cit., pág. 19. Ver Gerpe Landin, M., op. cit., pág. 166.

135 Memoria, cit., págs. 20 y 21 . El 16 de junio de 1982 se inició esta práctíca parlamentaria ante la Comisión de Justicia e Interior, presidida por el Presidente del Congreso de los Diputados y con asistencia del Presidente del Consejo Generál del Poder Judicial, quien informó y contestó a las preguntas de distintos grupos parlamentarios. Igualmente, el Consejo remite la Memoria al Gobierno -como eștá establecido en la ley-, a los ámbitos judiciales y a la opinión púlbica, iniciandó una política de transparencia sobre los reales problemas de la justicia dirigida a lós distintos cuerpos que la integran y al ciudadano, titular del derecho a la tutela judicial efectiva (Memoria, cit., pág. 29).

136 Cit. por Andrés leáñez, P., op. cit., pág. 17.

${ }_{137}$ La primera entiende que el Consejo tiene la posibilidad de tramitar la iniciativa a través del Gobierno para que la convierta en proyecto de ley o a través de las Cámaras como proposición de ley; a la contra, otro sector entiende que se trata de simple colaboración en las tareas pre-legislativas a través de una propuesta que el Gobierno - titular de la iniciativa- puede aceptar o rechazar libremente (posición manifestada por el Ministerio de Justicia ante el Pleno del Congreso el 7-X|1979). Estas posiciones doctrinales se debatieron en las Jornadas de Estudio organizadas por el Consejo y publicadas en 1983. Memoria, cit., pág. 109. 
sentido de uiniciativas o propuestas de ley como iniciativa o propuestas de disposiciones reglamentarias" durante todo su mandato ${ }^{138}$.

e.2) Igualmente el Consejo ejerce la potestad reglamentaria externa sobre las materias de su competencia, como potestad diferente a la atribuida por la ley para su organización y funcionamiento, "por ser el Consejo General el órgano de gobierno del Poder Judicial y no un mero instrumento de colaboración con el Poder Ejecutivo" ${ }^{139}$, basándose en la doctrina de los poderes implícitos que corresponden a la función de gobierno ${ }^{140}$.

e.3) El Consejo justifica su poca actividad en el ámbito disciplinario ${ }^{141}$ distinguiendo entre los defectos imputables a la conducta de los funcionarios - a los que se dirige la acción disciplinaria-, los debidos a exceso de trabajo o falta de medios cuya cobertura corresponde al Ministerio de Justicia, y las numerosas quejas originadas por las discrepancias de los denunciantes con determinadas actuaciones judiciales, ante las que el Consejo debe limitarse a informar sobre los recursos legales que tienen a su disposición ${ }^{142}$.

e.4) Respecto a la selección, formación y perfeccionamiento de todo el personal judicial, el Consejo traza una política crítica con la actuación anterior del Ministerio de Justicia, tendente a cubrir objetivos que considera prioritarios y abandonados: numerosas vacantes; programas $y$ sistemas de selección sin renovar en muchos años; despreocupación por la permanente formación de los fun-

138 Así constan en las Memorias de 1982, 1983, 1984 y 1985.

139 Memoria, cit., pág. 109. Así consta en las Memorias correspondientes a todo el periodo; en la de 1985 alude a que "actuando la potestad reglamentaria que, como órgano de gobierno del Poder Judicial, le correspondía, por imperio de lo establecido en el artículo 122.2 de la Constitución y del artículo $5 .^{\circ}$ de la $\mathrm{L}$. $O$. $1 / 1980 \ldots 1$. . Memoria de 1985, pág. 238.

140 Poderes implícitos que rechazará el TC en la Sentencia 108/1986, de 29 de julio, F. J. 25 y 26.

${ }^{141}$ Es precisamente este punto, que se considera abandonado como consecuencia del corporativismo generado por la forma de elección de los Vocales judiciales establecida en la Ley Orgánica de 1980, el más criticado por los defensores del nuevo sistema de elección en el debate sobre la LOPJ de 1985.

${ }_{142}$ Memoria de 1985, págs. 250-251. 
cionarios; ineficacia de la Escuela Judicial, con modesto presupuesto, profesorado mal retribuido, inexistencia de cursos y conferencias, etc. En respuesta a estas necesidades, el Consejo arbitra numerosas medidas tendentes a cubrir estos objetivos ${ }^{143}$.

El primer Consejo realiza un esfuerzo muy notable de conocimiento de la realidad judicial y de búsqueda de soluciones a problemas endémicos con vistas a la reestructuración de la Administración de Justicia ${ }^{144}$; sin embargo, sus continuas reivindicaciones van generando enfrentamientos con los distintos Gobiernos que acusan al órgano del ejercicio de compe: tencias que no le corresponden. Será un proceso de 5 años que terminará con el desapoderamiento del Consejo establecido en la Ley Orgánica de $1985^{145}$, que justifica, en mucha mayor medida que el nuevo sistema de elección, la actitud del segundo Consejo que se verá a continuación.

\section{El segundo Consejo General del Poder Judicial (1985-90)}

El segundo Consejo General presenta en 1990 una Memoria concebida como balance general del quinquenio, que es una laudatio a las metas alcanzadas y al grado de entendimiento logrado con todos los poderes del Estado. Frente al reivindicativo Consejo anterior, el órgano que ejerce su mandato desde 1985 a 1990 es una institución embridada por la Ley Orgánica del Poder Judicial que no se sale un ápice de la vía marcada por ésta.

a) Frente a la pretensión anterior de elaborar una política judicial autónoma, el segundo Consejo alude prudentemente a la conveniencia de una "mayor participación" en el diseño y organización del funcionamiento del Poder Judicial, que corresponde al Gobierno ${ }^{146}$.

143 Memoria de 1982, pág. 117.

144 En 1985 publica un compendio estadístico de la labor realizada por los órganos judiciales durante el cuatrienio 1981-84, con la siguiente finalidad: indicar la evolución de cada órgano judicial y sus disfuncionalidades; resaltar una curva geométrica indicativa, con proyección de futuro, $y$, como resumen, contar con una base sólida con la que afrontar la adopción de las medidas que requiera la reestructuración de la Administración de Justicia. Compendio estadístico de la labór realizada por los órganos judiciales durante el cuatrienio 1981-1984, CGPJ, Madrid, 1985, pág. 7, Introducción.

${ }_{145}$ Pronto va a surgir el enfrentamiento entre el Consejo y el Gobierno de UCD, consecuencia de la amplitud de competencias ejercidas por aquél. Ver nota 94.

146 Memoria de 1990, pág. 24. 
b) En oposición a la idea anterior del Consejo como representante del Poder Judicial, en pie de igualdad con el Ejecutivo, el actual órgano se refiere a la importante colaboración con aquél, canalizada a través del Ministerio de Justicia, y que se manifiesta en la aceptación de la relación de necesidades de la Administración de Justicia que le es enviada ${ }^{147}$.

e) Respecto al valor de la Memoria señalada anteriormente, el segundo Consejo presenta este documento como mero instrumento de información elevado a los representantes del pueblo, acto de especial trascendencia política desde la perspectiva de la cooperación entre los poderes del Estado; a través de este informe las Cámaras conocen la situación real de la justicia y su nivel de eficiencia ${ }^{148}$.

d) Olvidada la pretensión de ser titular de iniciativa legislativa, el Consejo insta al Gobierno, a través del Ministerio de Justicia, para que en el ejercicio de su "legítima facultad" introduzca en el Parlamento los proyectos de ley necesarios ${ }^{149}$. Respecto a la potestad reglamentaria, asume la competencia que le concede el Tribunal Constitucional respecto al desarrollo de la ley orgánica en relación al estatuto de jueces y magistrados y la ejerce en numerosos acuerdos reglamentarios, en defensa de la independencia de jueces y magistrados frente a las influencias del Ejecutivo; claro está que manifiesta que "no detecta problemas, actitudes ni conductas que puedan contradecir esa independencia" ${ }^{150}$.

e) Finalmente, en el limitado ámbito de formación y perfeccionamiento de jueces y magistrados que le concede la ley, considera que ha existido una perfecta sincronización con el Centro de Estudios Judiciales - con la colaboración del Ministerio de Justicia-, con los Gobiernos Autónomos y con las Universidades $^{151}$.

f) Como resumen, la conclusión del propio Consejo sobre la importancia de lo logrado mediante la cooperación, hasta tal punto que "la justicia española ha dejado de adolecer de su

\footnotetext{
147 Memoria, cit., pág. 20.

148 Memoria, cit., pág. 13.

149 Memoria, cit., pág. 21.

150 Memoria, cit., pág. 14

151 Memoria, cit., pág. 12
} 
crónica anemia en medios materiales y personales» ${ }^{152}$. Es decir, frente a la tensión anterior, la colaboración actual, aprovechando, lejos de un autogobierno de la judicatura no reconocido por la Constitución, "cuanto de positivo comporta la existencia de este órgano de gobierno, autónomo de otros poderes, del Poder Judicial». En este sentido, desea que, dentro de esa cooperación institucional, se abran los cauces legales para completar las atribuciones del Consejo en todo lo referente al estatuto judicial, lo que será tarea del próximo Consejo ${ }^{153}$.

Si el primer Consejo del Poder Judicial creó una posición institucional alejada de las previsiones constitucionales, debido a la ambigüedad de la Ley Orgánica de 1980, entre otras razones, el segundo Consejo conoce perfectamente sus limitaciones, evita cualquier enfrentamiento con el resto de los poderes e inicia, muy prudentemente, una actitud de asumir las limitadas competencias que le corresponden; sin embargo, deja al órgano que le sucederá - según parece entenderse- el desarrollo de aquéllas.

Así como el primer Consejo puede calificarse de activo y conflictivo, el segundo parece vaciado de toda fuerza: atacado desde su nacimiento con la acusación de politización y dependencia del partido político mayoritario, desposeído de numerosas competencias por la Ley Orgánica de 1985, reducido a los límites coincidentes con el mínimo constitucional, este órgano es incapaz de actuar de otra forma; pero en su última Memoria parece instar a su sucesor a reivindicar y ejercer las competencias que le quedan.

\section{El tercer Consejo General del Poder Judicial (1990-1995)}

La Memoria de 1991, primera elaborada por el tercer Consejo, es curiosa; lo es porque manifiesta un nuevo perfil del órgano de gobierno,

152 Memoria, cit., pág. 22.

${ }^{153}$ Memoria, cit., pág. 24. Se refiere el Consejo a necesarias modificaciones de la Ley Orgánica del Poder Judicial, señalando en concreto una clarificación de la regulación de la responsabilidad de los jueces y la superación de lo que aún persiste de la antigua concepción funcionarial de la carrera, buscando que los más capaces sirvan los puestos de más responsabilidad mediante los necesarios estímulos para la formación y especialización. 
diferente al mostrado por el anterior, $y$, sin embargo, las acusaciones de los medios de comunicación sobre los intentos de su Presidente por controlar la institución y no plantear problemas al Gobierno, son constantes ${ }^{154}$.

a) En-la Memoria se manifiestan tres ideas rectoras de la actividad del órgano, tendentes a "dar un paso adelante en la consolidación del Consejo " "155: su consideración de órgano constitucional, el pleno ejercicio de las competencias atribuidas y la adecuación de la organización y estructura interna para el mejor cumplimiento de aquéllas. El Consejo se declara órgano constitucional, y no de mera relevancia, por el reconocimiento que de tal naturaleza hace la Ley Orgánica del Tribunal Constitucional 156; ello implica "la plena participación" en la dirección de la actividad del Estado referida a la justicia, debido a la información privilegiada que recibe en el ejercicio de sus competencias, lo que le sitúa en una posición preferente a la hora de uconocer las necesidades de la Administración de Justicia y marcar los objetivos prioritarios".

Igualmente, su naturaleza de órgano constitucional ha de verse reflejada en el presupuesto, cuya elaboración, pese a no gozar de autonomía, "es acto de especial trascendencia... debido a la política judicial que el Consejo está llamado a desempeñar" ${ }^{157}$. Se exige, pues, un presupuesto adecuado, con

154 Desde el inicio del mandato, rara es la semana en que no se manifiestan críticas en este sentido a través de la prensa. En concreto, el nuevo Reglamento de organización interna, que se está discutiendo en el momento de redactar estas líneas, ha generado múltiples acusaciones al Presidente del Consejo, en el sentido de que pretende reforzar de tal modo sus competencias que pueda tener sometido al órgano, a través de tres puntos esenciales: el Presidente como portavoz único, el control absoluto, desde la mayoría, de todas las Vocalías y la regulación rígida del secreto en las actuaciones de los miembros. Ver P. UrBano: "La muerte del Poder Judicial», El Mundo, 2-11-92. Por otro lado, y con motivo de la renovación parlamentaria de varios miembroś del Tribunal Constitucional, el portavoz del Grupo Parlamentario Popular en el Congreso de los Diputados ha manifestado su negativa a negociar con el Grupo mayoritario mientras no se frene la actuación de $P$. SA LA al frente del Consejo General del Poder Judicial, pretendiendo dotarse de más poderes con un nuevo Reglamento; ello ha sido calificado de golpe de mano del Gobierno para evitar cualquier problema con el Consejo. Ver, por ejemplo, Diario 16 de 10-II-92. Es necesario esperar a que finalice la discusión de la norma en el Pleno del Consejo para comprobar o rechazar tan sombrias perspectivas.

155 Memoria 1991, pág. 9.

156 Creo que es el único argumento que lo avala. Ver epígrafe C. 1 de este trabajo.

157 Memoria, cit., pág. 12. 
lo que supone de atención del Gobierno al anteproyecto elaborado por el Consejo. Frente a la reivindicación directa del primer Consejo sobre la dirección de la política judicial y la coordinación deseada por el segundo, el órgano actual exige participación plena en las decisiones que tome el Gobierno por el especial conocimiento de las necesidades y carencias de la Administración de Justicia; ello supone que el Consejo ha de ser oído y atendido.

b) Su situación, señalada, en el sistema político, implica «una interpretación extensiva de sus competencias y el ejercicio de todas cuantas facultades se atribuyen al órgano de gobierno del Poder Judicial»" ${ }^{158}$.

La Memoria da una importancia prioritaria a la formación y selección de jueces y magistrados, a la contribución al proceso legislativo y a la inspección.

c) Se parte de la interconexión esencial entre la formación y la selección, por lo que los criterios del Consejo han de ser decisivos a la hora de proceder a ella. Por tanto, aunque en este documento no se reivindica esta competencia, se exige el papel relevante del Consejo, puesto que «no es concebible una adecuada política de formación que no tenga en cuenta los criterios de selección", y a la inversa ${ }^{159}$.

d) Respecto a la inspección, se le da un especial relieve como función preventiva que no se agota en la actividad sancionadora, sino que supone información para conocer y valorar el funcionamiento de la justicia y es el soporte para la elaboración de la relación de necesidades que se envía al Gobierno y. de la Memoria que se presenta ante el Parlamento ${ }^{160}$. Contri-

158 Memoria, cit., pág. 13.

159 Memoria, cit., pág. 14. Ver El País de 3-X-91, que recoge la información sobre la presencia de P. Sala en la Comisión de Justicia e Interior del Congreso, con motivo de la presentación de la Memoria de 1990 (última del Consejo anterior). Los Diputados K. Garmendia (EE), J. Azcárraga (EA), J. A. Souto (CDS), P. Castellano (IU) y F. Trillo (PP) reclaman la atribución de más competencias al Consejo y, en concreto, la competencia exclusiva para la selección de los nuevos jueces; no toman parte en la petición PNV y CiU, mientras que el Grupo Parlamentario Socialista considera que son suficientes las facultades atribuidas al Consejo para que cumpla su misión, aunque manifiesta su postura abierta a reflexiones más profundas. Por su parte, el Presidente del Consejo entiende que selección y formación son aspectos inseparables. El País, Diario 16 y El Mundo, 3-X-91.

160 Memoria, cit., pág. 16. 
buye, pues, de forma importante a ese conocimiento privilegiado que tiene el Consejo, que le sitúa en una posición especial ante los poderes públicos.

e) También es esa información privilegiada el fundamento para su contribución al proceso legislativo desde la información -esencial-sobre los anteproyectos de ley en relación al ámbito judicial. El Consejo, pues, pone especial acento en la atención que el Gobierno ha de prestar a sus criterios.

f) Por último y como consecuencia de lo dicho, expone la necesidad de una nueva estructura interna y una modificación de las actuales normas de organización ${ }^{161}$ para adecuar la institución al importante papel que está dispuesto a asumir.

Lo que se desprende de la lectura de esta primera Memoria del tercer Consejo es que el órgano, superado el desconcierto originado por la Ley Orgánica del Poder Judicial, conoce su posición institucional, la valora e intenta ejercer sus competencias en toda su amplitud; evita enfrentarse al Ejecutivo, pero reivindica la atención preferente que precisan sus criterios en cada uno de los ámbitos de actuación, incluso a la hora de decidir la política judicial. Las perspectivas teóricas son buenas; sin embargo, hay que observar su actuación y, sobre todo, esperar a que se apruebe el polémico Reglamento sobre el que se ciernen tan malos augurios, pues mediante esta norma sí que podría hacerse efectiva la influencia del Gobierno a través de su mayoría en el Consejo, en el día a día de sus actuaciones.

\section{F) CONCLUSIÓN}

Sobre la dependencia y la ineficacia del Consejo General del Poder Judicial se ha vertido mucha tinta desde 1985; sin embargo, creo que existe un confusionismo respecto a lo que realmente es esta institución, que impide valorar adecuadamente su trayectoria.

a) Como punto de partida, es necesario subrayar nuevamente que el Consejo tiene la única finalidad de preservar la carrera

161 Reglamento de organización y funcionamiento de 22 de abril de 1986, actualmente vigente. Ver nota 154. 
profesional del juez de presiones gubernamentales; no se puede perder de vista esta idea esencial.

b) El primer órgano de Gobierno, como consecuencia de una regulación ambigua, se consideró titular de amplias competencias que no encuentran su justificación ni en la Constitución ni en el Derecho comparado ni en la exigencia histórica y que van a generar enfrentamientos y recelos con los distintos Go: biernos.

c) De la práctica señalada se derivará un desapoderamiento del Consejo por la Ley Orgánica del Poder Judicial, privándole de competencias que no le correspondian, de alguna otra que debería tener - ya señaladas a lo largo del trabajo-y primando la decisión del Ministerio de Justicia salvo en el mínimo exigido por la Constitución; por ello, el Consejo carece de la última decisión en múltiples aspectos, lo que se confunde numerosas veces con la dependencia generada por la forma de elección.

d) Ésta es, en mi opinión, la razón fundamental de la situación actual del órgano de gobierno en mucha mayor medida que el sistema de elección de los Vocales. La Ley Orgánica ha convertido al Consejo en un órgano instrumental con competencias administrativas y consultivas; ¿debe ser diferente? Creo que no, con matizaciones, lo que no significa que su función no sea básica para lograr una justicia independiente, esencial en un Estado de Derecho.

e) Junto a lo dicho anteriormente, hay que señalar que la nefasta práctica parlamentaria llevada a cabo en la propuesta de los Vocales del Consejo ha agravado la imagen de dependencia e ineficacia del órgano y ha llevado a mitificar la elección mixta anterior por identificación con un órgano muy activo, con muchas más competencias que el actual, unas que tenía realmente y otras que se interpretó le correspondían. La modificación de la práctica es fundamental, pues afecta de tal forma a la imagen de las instituciones cuya integración corresponde al Parlamento que daña de manera irreparable todo el sistema político; el control difuso que ejerce la opinión pública puede ser un medio eficaz para ello, con todos los interrogantes que se quiera sobre la capacidad del Parlamento para variar su forma de actuar en un Estado de partidos como el actual.

f) La supeditación del Consejo al Gobierno en numerosas materias se debe, pues, a la regulación establecida en la Ley Orgá- 
nica en mucha mayor medida que a la dependencia que puede generar la forma de elección, ésta o aquélla, ya que los partidos políticos llegan directamente a los grupos parlamentarios pero también, indirectamente, a las asociaciones profesionales; hay que recordar que la mayoría existente en el primer Consejo no coincidió en ningún momento con la mayoría gubernamental, con lo que se encontraba en una situación menos sensible a las influencias gubernamentales; en el hipotético caso de que existiera esa coincidencia, la situación podría ser paralela a la actual. Al margen de la forma de elección, la ley ha rodeado a los Vocales de unas cautelas que les permitirán un ejercicio razonablemente independiente de las únicas competencias que le corresponden: el estatuto de jueces y magistrados.

g) Hechas las matizaciones anteriores, hay que añadir que el Consejo tiene un limitado, aunque esencial, ámbito de actuación; el ejercicio de sus competencias le permite lograr una información privilegiada sobre las necesidades de la justicia, por lo que los criterios manifestados a través de la Memoria enviada al Parlamento, de la relación de necesidades dirigida al Gobierno y de los informes sobre anteproyectos de ley y disposiciones generales, deben ser atendidos de manera especial y considerados a la hora de elaborar la política judicial.

Madrid, marzo 1992. 